AQU Journal of Islamic Economics, Vol. 1 No. 1, pp. 39-88 (June 2021)

DOI:10.52747/aqujie.1.1.18

E-ISSN 2788-5550 / ISSN 2788-5542

$$
\text { نحو تطوير نظام شبكي للوقف الإسلامي المتناهي الصغر: الآليات والأدوات }
$$

TOWARDS THE DEVELOPMENT OF A FRAMEWORK

FOR ISLAMIC MICRO-WAQF: MECHANISMS, METHODOLOGY AND MODEL FORMULATION ${ }^{1}$

$$
\text { جامعة محمد البشير الإبراهيمي برج بوعريريج، الجزائر }
$$

\title{
Rahim Hocine
}

Université Mohamed El Bachir El Ibrahimi de Bordj Bou Arréridj, Algeria

\begin{abstract}
ملخص
هذا البحث له هدف مزدوج: أولا، علمي تنظيري، يتمثل في تقديم مساهمة متواضعة في

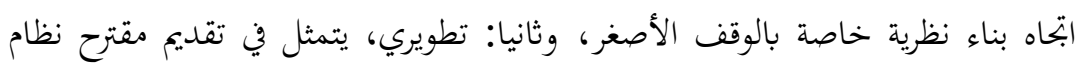

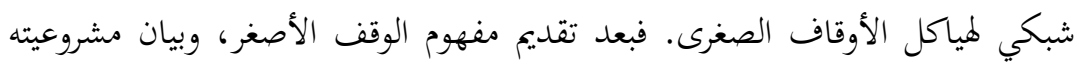

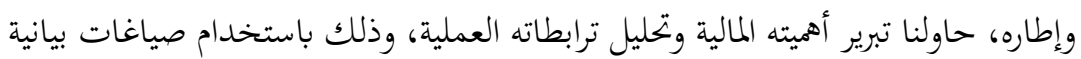
ورياضية، مع تقديم أمثلة عن كيفية حساب الحصيلة التقديرية للأوقاف الصغيرة، كما قدمنا مقترحا يتعلق بإقامة نظام شبكي لذلك، يستهدف ربط مختلف هيك هياكل الوقف الصغيرة، وذلك انطلاقا من مبدأ التعاون والتعاضد في سبيل تعظيم المنفعة الاجتماعية والاقتصادية المتوقعة من هذا النظام.
\end{abstract}

${ }^{1}$ Article received: Feb. 2019; article accepted: May 2021 


\section{Abstract}

This article has a twofold purpose: firstly, to make a modest scientific contribution towards constructing a specific theory of micro-waqf, secondly to present a proposal concerning the implementation of a network system of micro-waqf structures. After introducing the concept of micro-waqf and its jurisprudence, we tried to justify its financial importance and analyze its operational linkages, through a schematic and mathematical representations, giving an example on the calculation of the estimated recipe of micro-waqf, We brought forward a proposal to developing an "micro-waqf network system" that will link the different structures concerned by this type of waqf, within the framework of the cooperation and synergy principles, in order to maximize the social and economic utility expected from this system.

\section{الكلمات الدالة: الوقف، الوقف الأصغر، شبكة الأوقاف الصغرى، المالية التضامنية.}

Keywords: Waqf, Micro-Waqf, Micro-Waqf Network System, Solidarity-Based Finance.

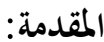

$$
\begin{aligned}
& \text { يقوم النظام المالي الإسلامي على ركنين أساسيين: ركن بتحاري ربحي، وركن تضامني }
\end{aligned}
$$

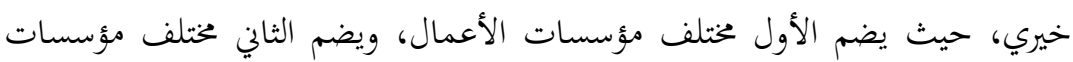

$$
\begin{aligned}
& \text { وآليات التضامن والتكافل. والوقف الإسلامي، إلى جانب الزكاة ومختلف أشكال }
\end{aligned}
$$

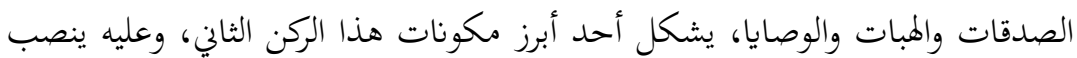

$$
\begin{aligned}
& \text { اهتمامنا في هذا البحث، وذلك من خلال محاولة المساهمة في تطوير نموذج خاص بالوقف } \\
& \text { الأصغر. } \\
& \text { لقد شهد حقل المالية الإسلامية خلال العقود الأربعة الأخيرة طفرة غير مسبوقة، } \\
& \text { رافقتها هبّة لافتة في مجال البحث والتطوير والاجتهاد الفقهي، غير أن المتتبع لهذا المسار } \\
& \text { يدرك أن تلك الجهود انصبت في جلها على مجال المصارف وأسواق المال، والتي تندرج }
\end{aligned}
$$


نحو تطوير نظام شبكي للوقف الإسلامي المتناهي الصغر

ضمن الركن الأول، أي: قطاع الأعمال، بينما لم يهظَ بجال الوقف، وآليات القطاع

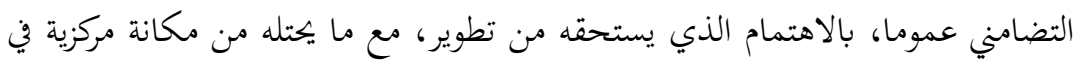
النظام المالي الإسلامي، وما ينطوي عليه من قوة كامنة من شأها بعث قطاع قائم بذاته، وهو القطاع الثالث، وإرساء قواعد لاقتصاد تضامني متين الأركان، من شأنه رفع غبن الفقر بن

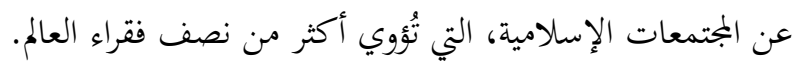
يندرج هذا البحث في إطار مسعى تطوير نظام الوقف، الذي يمثل أبرز روافد المالية

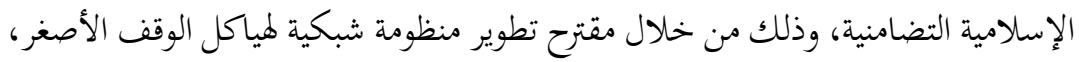

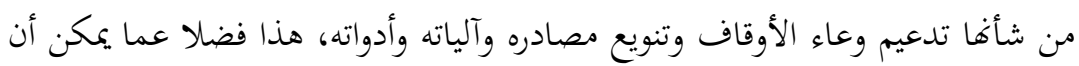
تتيحه من ترسيخ لثقافة الوقف وإشراك الجميع في الفعل الوقفي، بدلا من تعليقه على سخاء فئة الأغنياء والملالّك.

إشكالية البحث:

يمكن صياغة إثكالية هذا البحث من خلال التساؤل الآتي: كيف يمكن إرساء شبكات مهيكلة للوقف المتناهي الصغر بالمجتمعات الإسلامية، بما يحقق فاعلية أكبر لقطاع

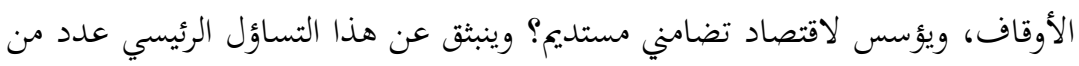

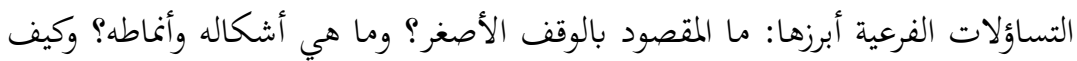
يمكن تبرير أهميته بالاستناد إلى الأدوات الكمية؟ ما مضمون مقترح شبكة الأوقاف المتناهية

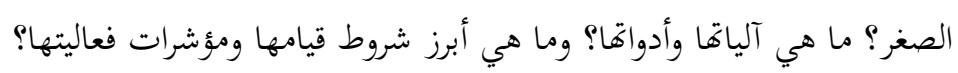

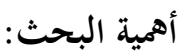

تنبثق أهمية هذا البحث من كونه يرمي إلى تطوير نمط آخر من الأوقاف، وهو الأوقاف الصغرى، أو بالأحرى تطوير نظام خاص بالوقف الأصغر، في ظل هيمنة ثقافة

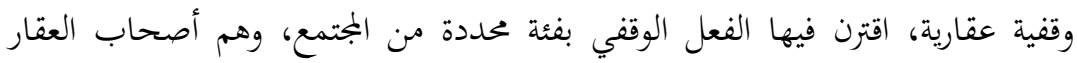

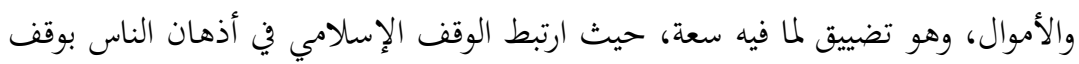
الأراضي والمباني لأغراض دينية، وحتى وقف المنافع والمنقولات، يكاد ينحصر في هذإنها 
المجال، كوقف المصاحف والكتب الشرعية، في حين أن الوقف الإسلامي تمتد منافعه لكل

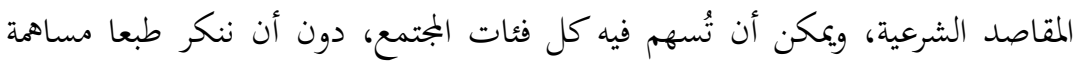
الوقف الإسلامي عبر العصور في شتى المجالات الاجتماعية والاقتصادية، ولاسيما في مجال التعليم والصحة ودعم بعض الفئات الهشّة، ولكن بمستوى أقل نسبيا من المجال الديني.

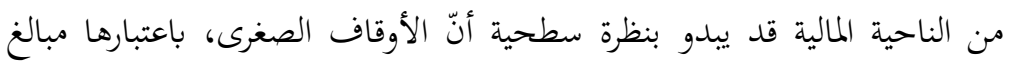

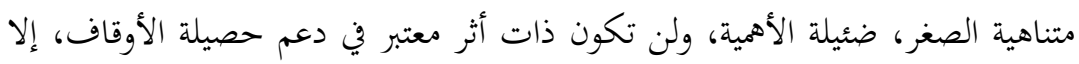

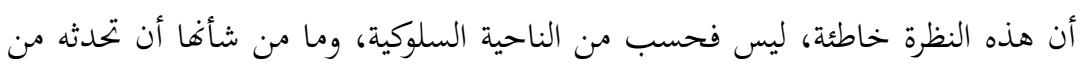

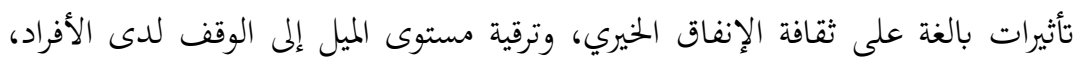

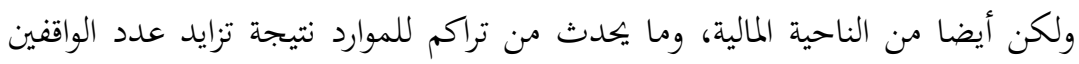

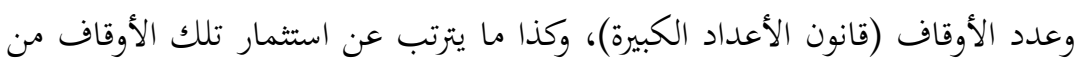
تراكم في الأموال ودعم للموارد الوقفية. ومن ناحية ثانية، تتجلى أهمية هذا البحث أيضا في ما يتضمنه من مقترح إقامة

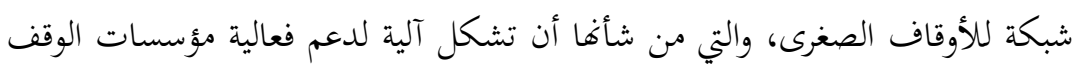

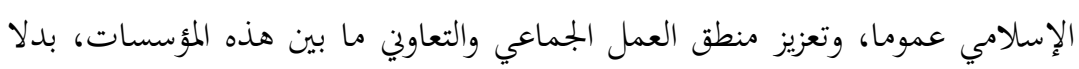
من وضعية العمل الانفرادي السائدة. ومن ضمن الشبكات التي يمكن بتسسيدها في هذا الإطار، على سبيل المثال، شبكة مؤسسات الوقف الأصغر لدعم المشروعات الصغرى،

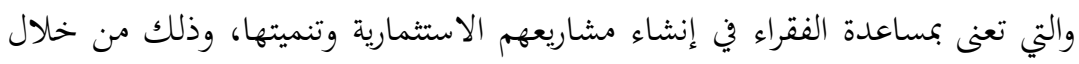

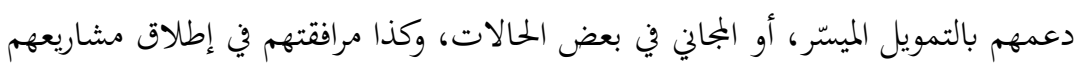
بالاستشارة والتوجيه، ضمانا لنجاح المشروع واستمراره.

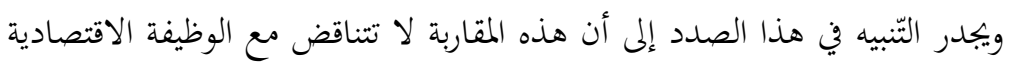

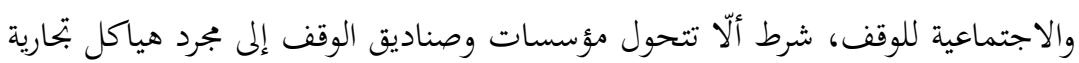

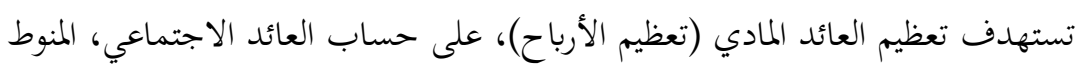


نغو تطوير نظام شبكي للوقف الإسلامي المتناهي الصغر

هما أصلا. فإذا كان بالإمكان تخصيص جزء من موارد الزكاة للفقراء لتأسيس مشروعاتم والخروج من بوتقة الفقر، فالوقف أولى بهذه الوظيفة الاقتصادية-الاجتماعية.

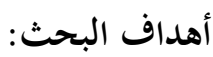

الهدف من هذا البحث مزدوج: هدف تنظيري وهدف تطويري. فمن الجانب العلمي

والتنظيري، يهدف البحث إلى تقديم إطار نظري لمقترح الوقف الأصغر، يشمل الجانبين الشرعي والاقتصادي والفني، في حين يتضمن الهدف التطويري تطوير نظام شبكي للأوقاف الصغرى، بما يتضمن ذلك من امتدادات تتعلق بالدور المتوقع من هذا النظام في التنمية الاقتصادية والاجتماعية والثقافية، والمساهمة في ترقية التمويل الاستثماري التضامني

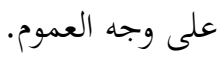

فمن خلال هذا البحث سنحاول عرض مقترح مشروع يتعلق بتطوير شبكة للأوقاف

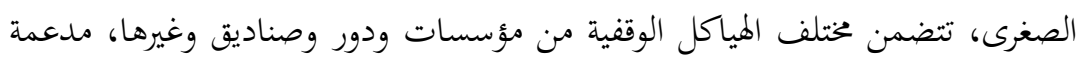
بشبكة افتراضية، باستخدام تكنولوجيات الإعلام والاتصال، تكون بمثابة آلية لتبادل الخبرات والمعلومات وبحسيد مبدأ التعاون والتضامن في الأعمال الحخيرية، لاسيما منها تمويل المشاريع الاجتماعية ودعم الفقراء في إطلاق مشاريعهم الاستثمارية وإدماجهم في مسار

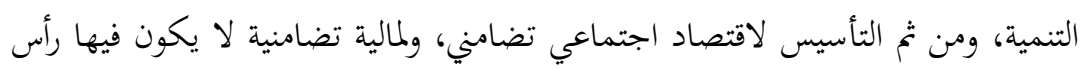
المال دُولَة بين الأغنياء حصرا.

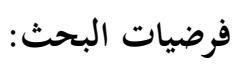
ننطلق في هذا البحث من الفرضيات الآتية:

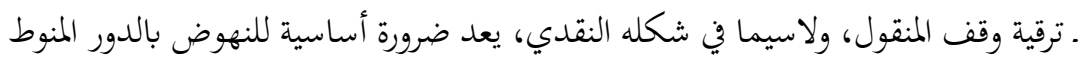

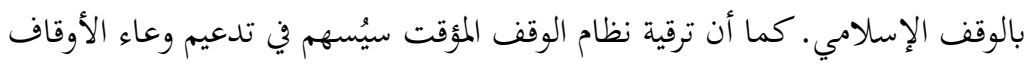
بالمجتمعات الإسلامية. . يمكن الأوقاف الصغرى أن تشكل رافدا بالغ الأهمية ضمن روافد المالية الإسلامية التضامنية. 
ـ تشكل شبكة الأوقاف الصغرى آلية فعالة لترسيخ السلوك الوقفي لدى مختلف الفئات من ناحية، ودعم الاستثمارات الصغرى للفقراء من ناحية ثانية. • يقتضي تحقيق فعالية آلية الأوقاف الصغرى توافر مجموعة من الشروط الموضوعية والذاتية، وتخضع هذه الفعالية إلى عدد من المؤشرات المرجعية.

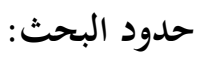

يهتم هذا البحث بمعالجة نمط محدد من الأوقاف، وهو الأوقاف الصغرى، والتي تندرج ضمن وقف المنقولات، وذلك في إطار أحكام الوقف الإسلامي عموما، وبالتالي فالمجتمع المستهدف هو الجمتمع الإسالامي بكافة أرجائه، كما أن طبيعة البحث بتعله غير متعلق بفترة زمنية محددة، فهو لا يتعلق بدراسة تحليلية للأوقاف خلال فترة زمنية محددة، بل يرمي إلى طرح صياغات للأوقاف الصغرى، وإمكانية قيام شبكة خاصة بها، يمكن. البناء عليها في مثل هذه الدراسات الميدانية، وفي التطبيقات العملية في ممارسات هياكل الوقف الأصغر بالبلدان الإسلامية.

منهجية البحث:

سيتم الاعتماد في هذا البحث بالأساس على منهج الاستباط، حيث إن المدف هو استنباط نظام جزئي للأوقاف قائم على منظور القيم الصغرى، وسنعتمد في استجلاء أهمية الوقف الأصغر على الأسلوبين الرياضي والتحليلي، كما سنعتمد أسلوب النمذجة، البيانية منها والرياضية، في إبراز أهمية مقترح شبكة الأوقاف الصغرى، حيث يساعد ذلك على ضبط المتغيرات والعوامل المحددة للوقف الأصغر، وكذا تحديد وتوضيح مختلف العلاقات الترابطية ما بين مختلف تلك العوامل والمتغيرات. كما أننا سنستعين في عدة مواضع بأشكال وخططات بيانية، بعضها يندرج في إطار النمذجة البيانية للمقترح. غير أننا سنعتمد أسلوبي: الوصف والتحليل في عدة جوانب، سواء في تقديم الوقف الأصغر وآلياته، أو في تحليل ترابطات مكوناته. 
نحو تطوير نظام شبكي للوقف الإسلامي المتناهي الصغر

خطة البحث:

ستتم معالجة هذا الموضوع من خلال المحاور الآتية، متوجة بخاتمة تتضمن أهم النتائج

والمقترحات:

- الإطار العام للمالية الإسلامية التضامنية والفعل الوقفي

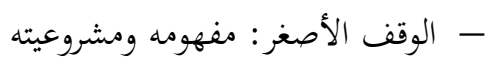

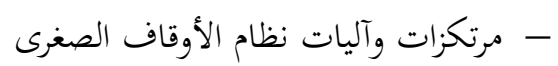

- الصياغة البيانية والرياضية للوقف الأصغر

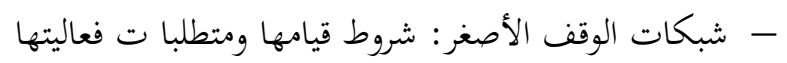

1- الإطار العام للمالية الإسلامية التضامنية والفعل الوقفي:

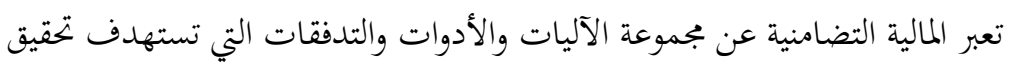

أهداف تكافلية على سبيل الإحسان، أي دون غرض ربكي، سواء أتم ذلك في إطار

مؤسساتي مرتبط بسياسات عامة ومنظمات حكومية أو غير حكومية، أم تم في إطار

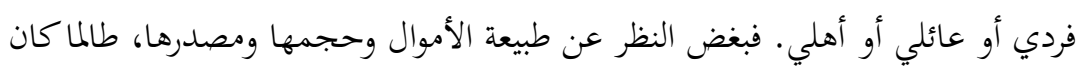

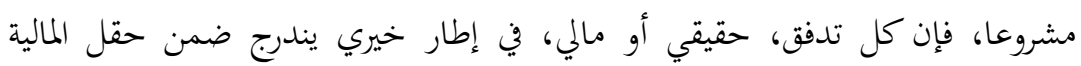
التضامنية.

ولئن كان هذا النمط من المالية يعد عريقا في القدم، إذ إنه مرتبط بالفطرة البشرية

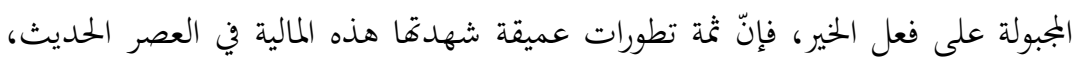

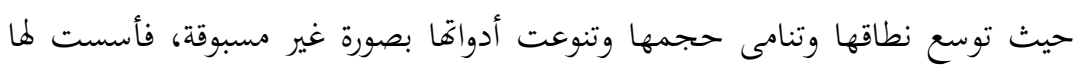
منظمات خاصة، أهلية وقومية ودولية، إنْ في شكل مؤسسات (foundations) أو في

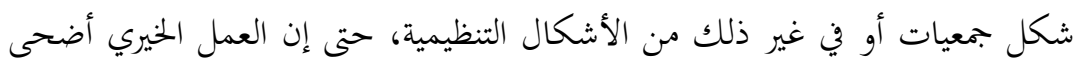

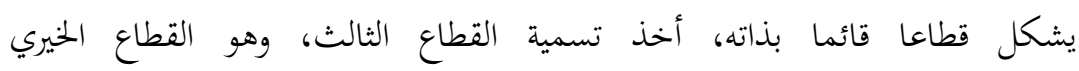

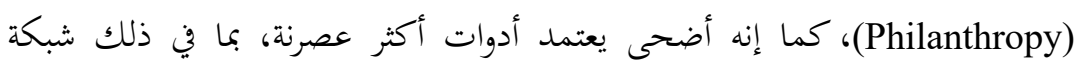
الإنترنت، ولم تبق تدخلاته مقتصرة على تقديم المساعدات الاستهلاكية، بل طالت مجالات إنهات 
الاستثمار، من خلال إنشاء مؤسسات للاستثمار الاجتماعي والاستثمار الخيري (Venture Philanthropy) مغادرة دائرة الفقر، ومن أبرز العوامل التي ساعدت على ذلك سمة الديمومة، التي تعد عاملا

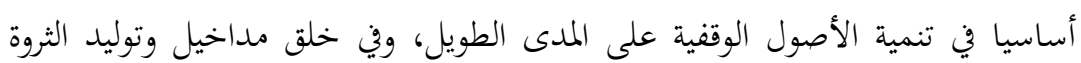
والمساهمة في تنمية المجتمع (Hamber, 2017, pp 37-60). ولئن كان حقل المالية التضامنية يضم مختلف أشكال التدفقات ذات الطابع الخيري،

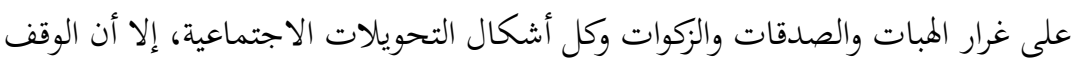
ظل يشكل أبرز روافد هذا النمط من المالية عبر العصور، في الشرق كما في الغرب، ولعل أهم مبرر لذلك طبيعة هذا النوع من التحويلات، التي تتسم بطابع الاستمرار وعموم الاستفادة، حيث إن الوقف يتعلق في الغالب بأصولٍ دائمة، وتنتفع به، على الأقل، فئة

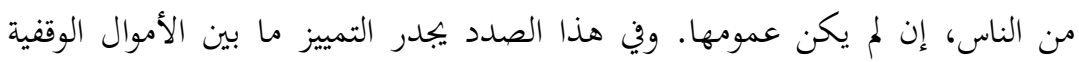

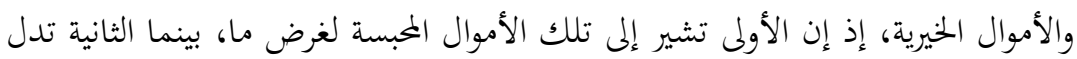

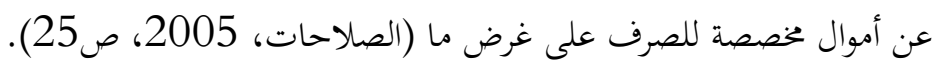
يدل مصطلح الوقف، الذي يقابله في الاستخدام الغربي مصطلح endowment، عن حبس أصل لغرض خيري بحت، سواء أكان ذلك لمصلحة عامة أم لمصلحة خاصة.

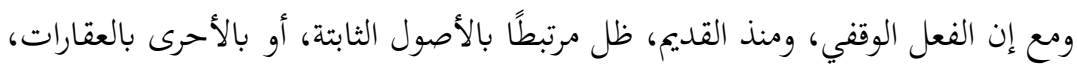

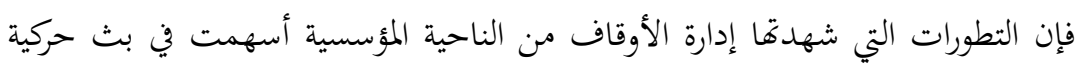

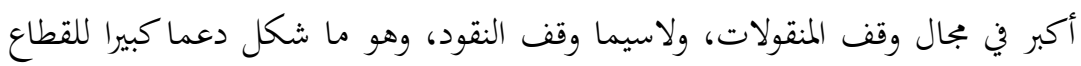
الخيري، ووسع من وعائه ونطاق تدخلاته. ولعل ما عزز هذا التوجه، على مستوى

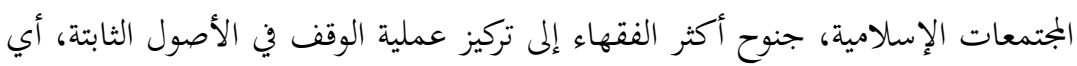

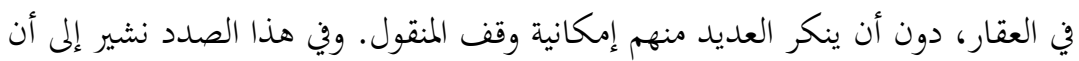

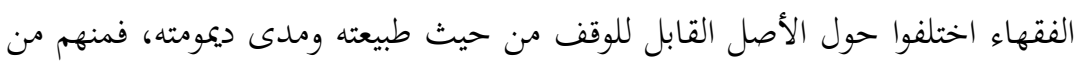
وسّع ومنهم من ضيّق. فأبو حنيفة حصر الوقف في العقار، ومنعه في المنقول، لأنه ليس 
نغو تطوير نظام شبكي للوقف الإسلامي المتناهي الصغر

له صفة التأبيد، ويجب أن يكون مملوكا، بينما وسعه المالكية لكل ما يُملكَ، فأجازوا الوقف

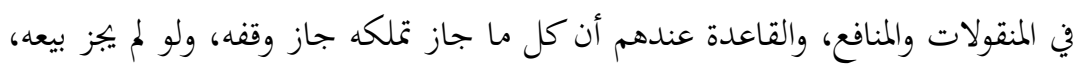

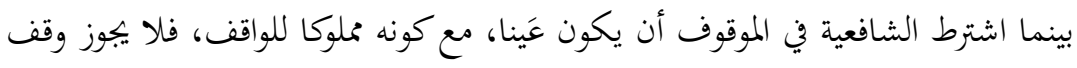

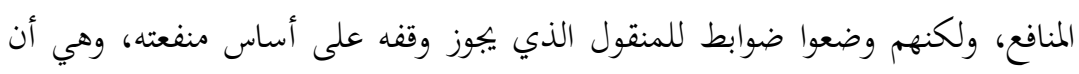

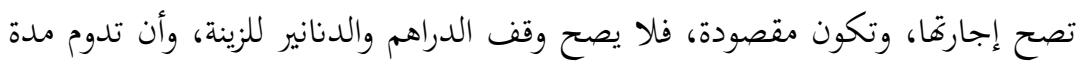
تقصد بالإجارة. أما الحنابلة فاشترطوا في المال الموقوف، إضافة وإلى كونه مملوكا، أن يكون

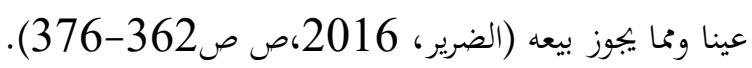

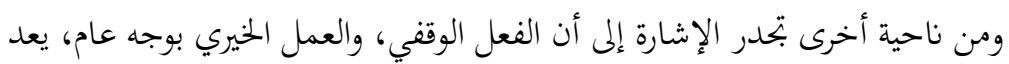

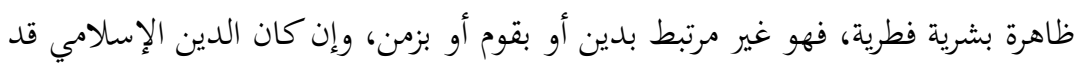

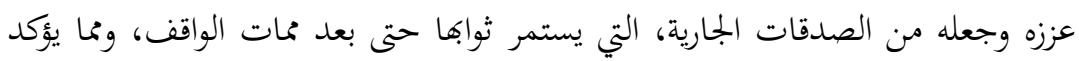
ذلك ما نقرأه في التجربة الغربية في هذا المجال. فعلى الرغم من أنه لا توجد تفسيرات

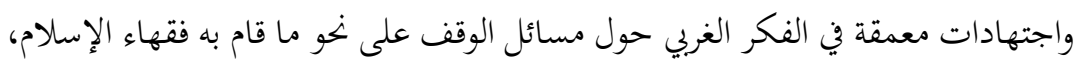

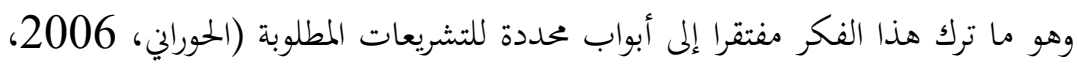
ص6)، إلا أن الغرب تمكن من الاستفادة كثيرا من الوقف كشكل مؤسسي في شتى

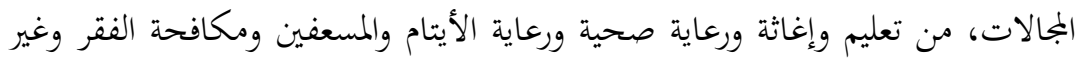

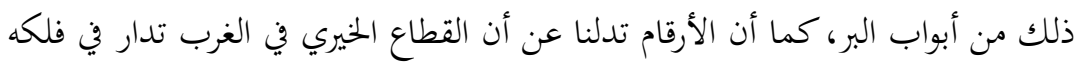
مليارات الدولارات، وتشرف عليه مئات الآلاف من المؤسسات ذات الغرض غير الربحي.

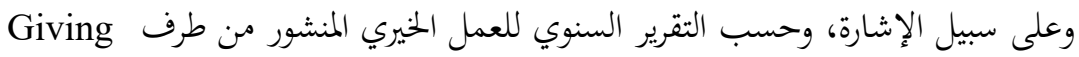
USA

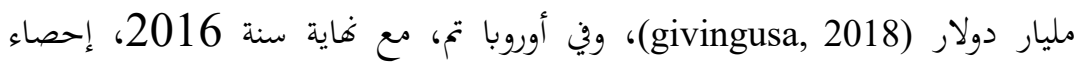

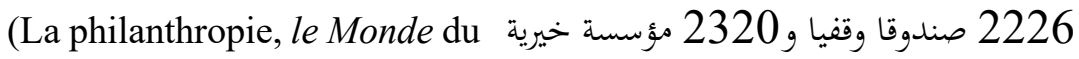
World Giving 06 juin 2017)

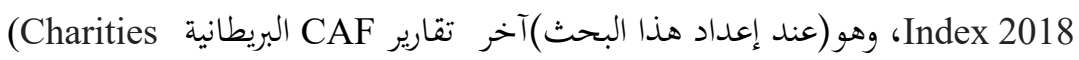


(cafonline, التي تعنى بتقديم مؤشرات العمل الخيري حول العالم Aid Foundation)

أما على مستوى العالم الإسلامي، فإن العمل الخيري والتضامني يعد ثقافة راسخة،

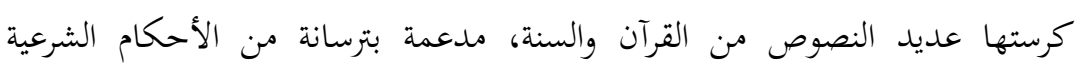

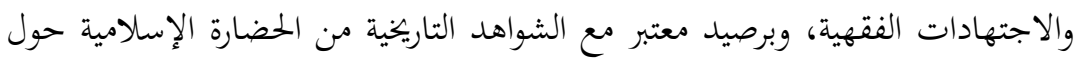
تنظيمات الوقف والزكاة وغيرهما من أوجه المالية التضامنية. وفي مجال الأوقاف نشير هنا، ونديا،

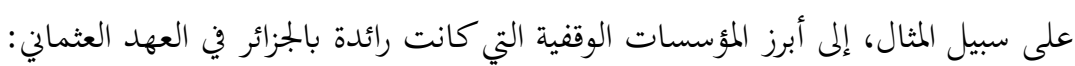

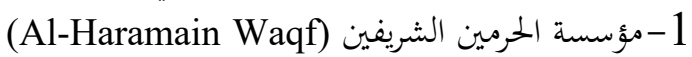

2-1 مؤسسة أوقاف الجامع الكبير (الأعظم) (Endowment Foundation Of the

Great Mosque)

3-أوقاف سبل الخيرات الحنفية (The Hanafi endowments of good means) 4- أوقاف مؤسسة بيت المال (The Baytul-Mal Endowment Foundation) 5-مؤسسة أوقاف الأندلسيين The Andalusian Endowment)

Foundation)

ومع ذلك فإن واقع الأوقاف بالبلدان الإسلامية يدلنا عن أنه ما يزال بحاجة ماسة إلى مأل هياكل مؤسسية أكثر تطورا وفاعلية، خاصة بالنظر إلى الإرث الحضاري والرصيد الثقافي

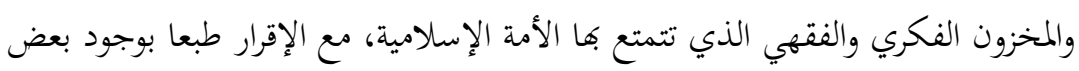
المؤسسات الرائدة في هذا المجال، تمكنت من إطلاق مشاريع هضوية وتنموية بالغة الأهمية،

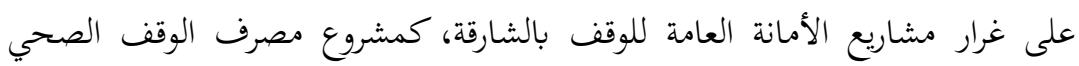
ومشروع الأسهم الوقفية (الذي يشمل 11 مصرفا)، ومشاريع الأمانة العامة للوقف بدولة

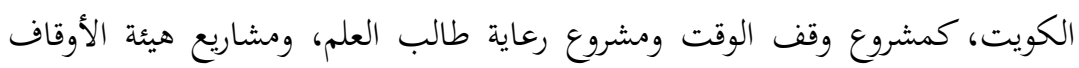

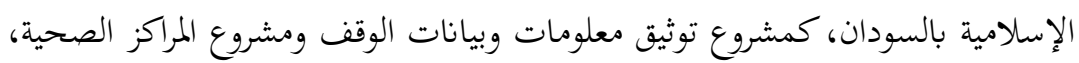

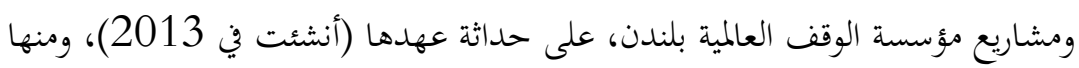

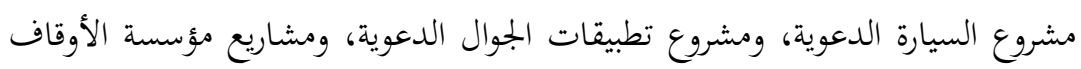
الوطنية بجنوب إفريقيا، ومنها مشروع السفر عبر القرآن. 
نو تطوير نظام شبكي للوقف الإسلامي المتناهي الصغر

\section{2- 2 الوقف الأصغر: مفهومه ومشروعيته}

يقصد بالوقف الأصغر: حبس مال متناهي الصغر على سبيل الإحسان لغرض ومنتروينه الانتفاع منه من طرف الغير، سواء أكان ذلك لمصلحة عامة (عامة الناس) أم لمصلحة

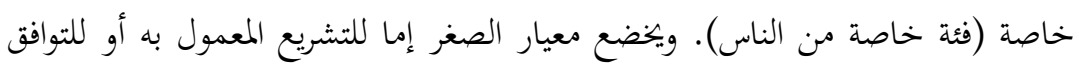

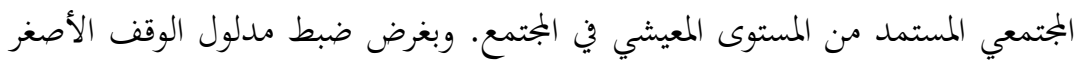

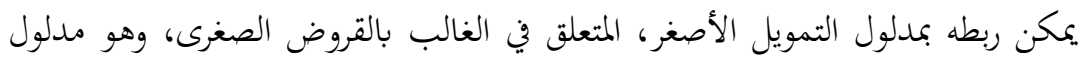

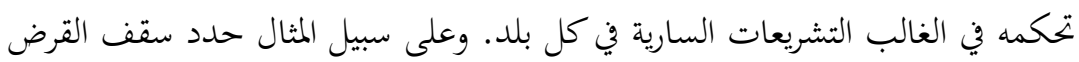
الأصغر بالجزائر بمبلغ مليون دينار جزائري، وهو موجه لفئة المواطنين دون دخل، أو ذوي دخل غير مستقر وغير منتظم، إضافة إلى النساء الماكثات بالبيت (الوكالة الوطنية لتسيير القرض المصغر ANGEM، ما هو القرض المصغر؟). تمثل الأوقاف الصغرى أحد مكونات المالية التضامنية الجماهيرية، أي التي يمكن أن أن التهرصي تشارك فيها كل فئات المجتمع، وهي تتعلق أساسا بوقف المنقولات، سواء أكانت في صورة

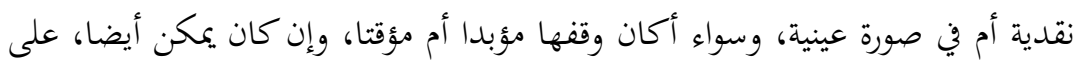

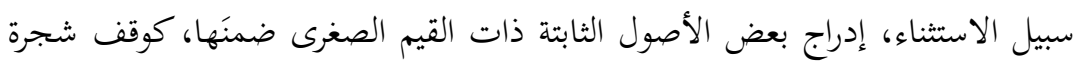
مثمرة على الطريق، أو وقف قطعة أرض صغيرة أو محل صغير.

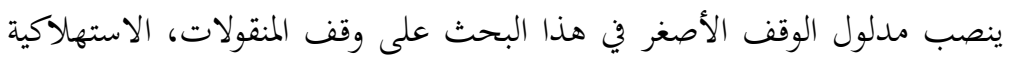
منها والاستثمارية، غير أن الاهتمام يتجه نهو تلك الموجهة للاستخدام الاستثماري، التي يمكن أن تدر عائدا، إنْ باستخدامها المباشر أو بتحويلها إلى أصول استثمارية لفائدة

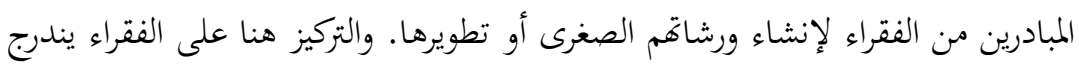

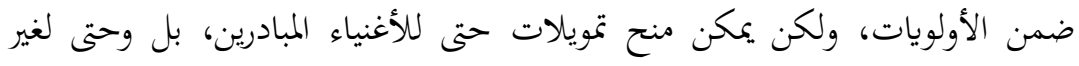

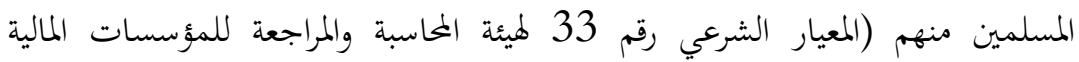
الإسلامية بخصوص الوقف). فالمقصود إذا هو "الوقف المنتج"، أي تعبئة موارد وقفية

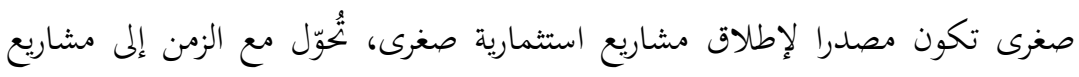


متوسطة وكبرى، وهو ما من شأنه أن يجعل من "الوقف الجماهيري" آلية لخلق الثروة ومكافحة الفقر وامتصاص البطالة، وذلك عبر توسيع نطاق محفظة المالية التضامنية ودعم منم

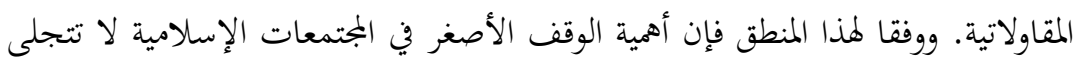
فحسب من كونه يمثل إحياء لسنة الوقف وواجب التكافل، ولكن أيضا في ما يتيحه بديلا

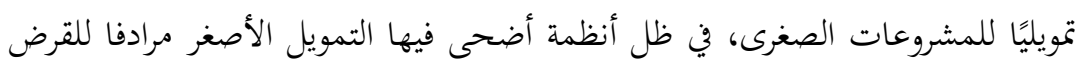

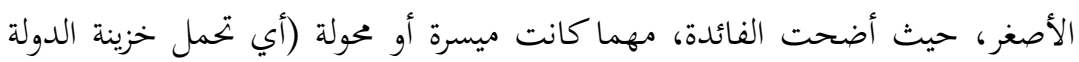
لفوائد القرض بحاه البنوك بدلا من المستفيدين)، بمثابة القلب النابض لأنظمة التمويل.

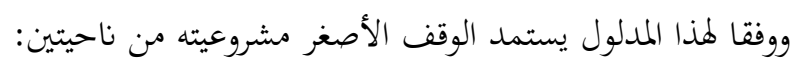
(1) المشروعية الدينية: وتتضمن هذه المشروعية شقين: ـ الثق الأول يتعلق بجانب واجب التكافل الاجتماعي، والنصوص، من القرآن والسنة، التي تحث على البذل والإيثار والتعاون والتآزر ما بين المسلمين عديدة، منها قوله تعالى:

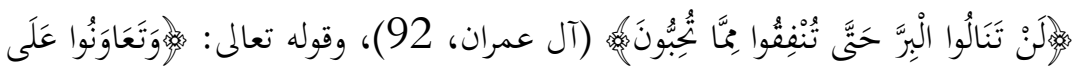

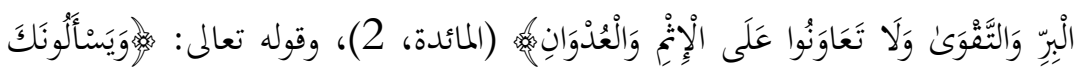

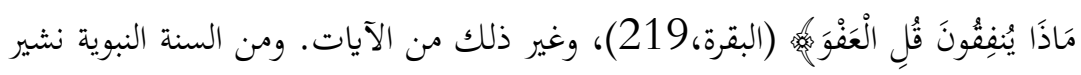

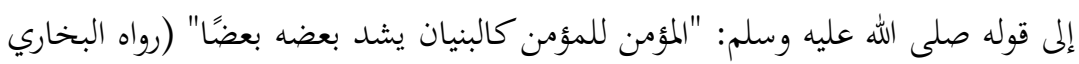
ومسلم)، وإلى الحديث الذي رواه مسلم عن أبي سعيد الخندري رضي الله عنه قال: (بينما

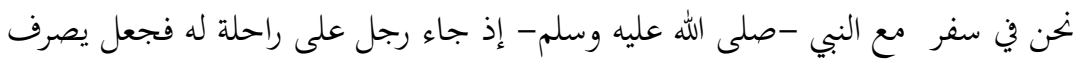

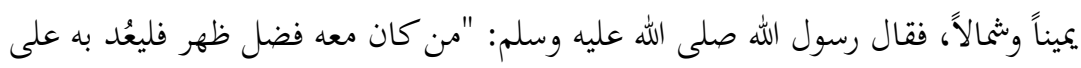

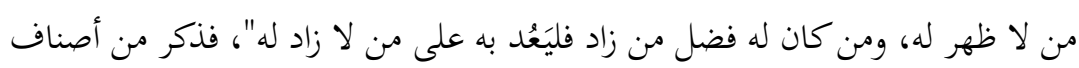

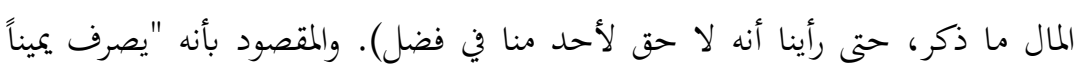

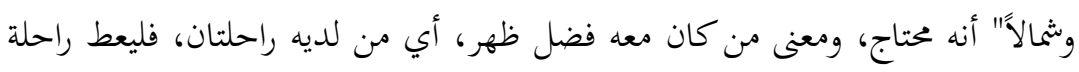
لمن يحتاج إلى راحلة. 
نحو تطوير نظام شبكي للوقف الإسلامي المتناهي الصغر

ـ أما الثق الثالي فيتعلق بالجانب الفقهي، وهنا نشير إلى أن جمهور الفقهاء على جواز

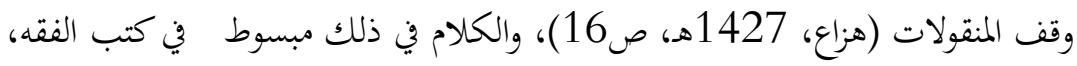
وبه أخذ مجمع الفقه الإسلامي الدولي، التابع لمنظمة المؤتمر الإسلامي (قرار مجمع الفقه

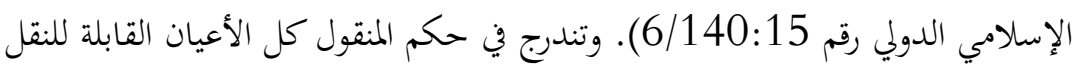

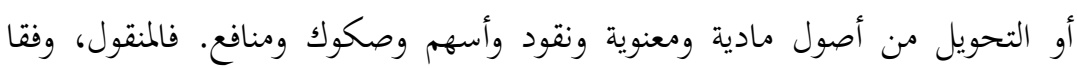

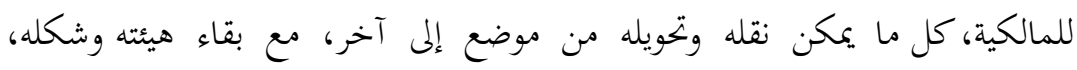

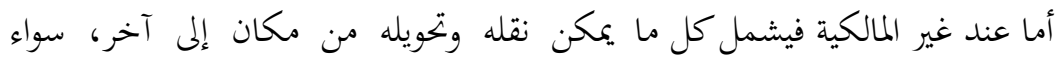

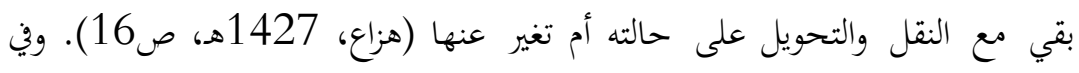
كل ذلك نجد سعة لدى الفقهاء، وقد استفاض في هذا المجال المعاصرون من الفقهاء والباحثين (قرار بجمع الفقه الإسلامي الدولي رقم 181 :19/7؛ قحف، 2009م؛ فياض، 1427هـ)، خاصة وأن باب الوقف يعد من أوسع الأبواب فتحا للاجتهاد. وبحدر

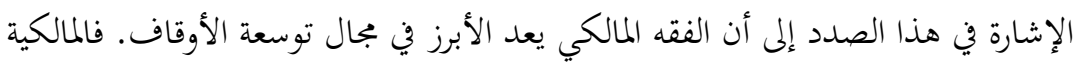

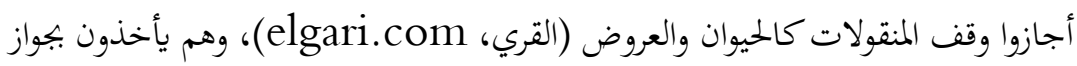
وقف الدراهم والدنانير لتسلف لمن يحتاج إليها، ويرد مثلها وقفا في محلها. وبالتالي يجيوز

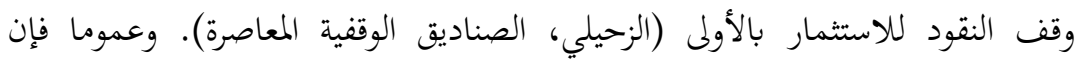

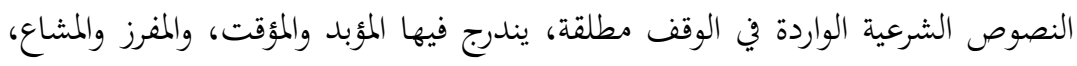

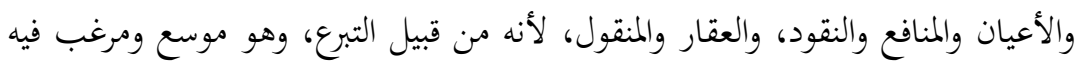
(قرار مجمع الفقه الإسلامي الدولي رقم 18 : 19/7).

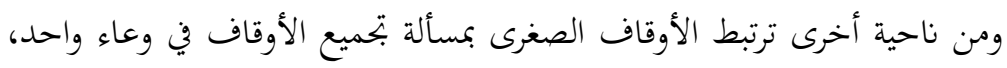
إذ أفها بمفرداتها لا تفي بالغرض المطلوب لاستثمارها. وفي هذا الصدد يمكن الاستناد أيضا

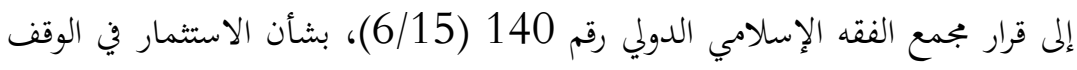
وفي غلاته وريعه، الذي أقر بأنه "لا مانع شرعا من استثمار أموال الأوقاف المختلفة في وعاء استثماري واحد بما لا يخالف شرط الواقف". مع التأكيد أننا، في بكثنا هذا، بصدد 
هيئات أو صناديق استثمار مشترك، أي: وقف مؤسسي معتمد من طرف الدولة، وليس أفس بصدد أفراد يقومون بتجميع أوقاف بصورة منعزلة. (2) المشروعية الاقتصادية والاجتماعية والسلوكية: يشكل الوقف الأصغر مدخلا لتحقيق الوظيفة الاقتصادية والاجتماعية للوقف من جهة، وآلية لإشراك الجميع (واقفون وموقوف عليهم) في مسار التنمية من جهة ثانية. فالوقف في أصله ومقصده غرضه تعاوني

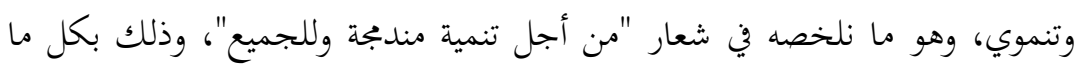
تحمله التنمية من مدلولات: بشرية، اقتصادية، اجتماعية وثقافية. وإذا كانت المسؤولية الاجتماعية أضحت من مؤشرات قياس أداء منظمات الأعمال

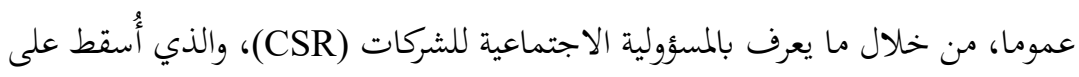

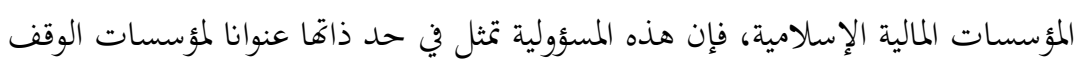
الإسلامي. ولئن كان تناول الدور الاجتماعي للأوقاف من المواضيع المسهب فيها منذ فئل فئل

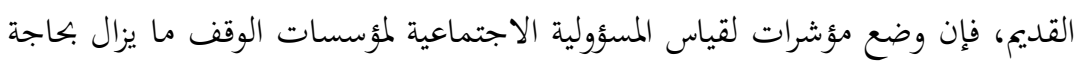
إلى اجتهادات. وفي هذا الصدد نشير إلى أن الأبحاث والدراسات التي تربط المسؤولية الاجتماعية للمؤسسات بالوقف تعد قليلة نسبيا، لاسيما الدراسات الميدانية منها .(Darus et al, 2017, pp959-965) ومن جانب آخر تُستمد المشروعية الاقتصادية والاجتماعية للوقف من الفرص المتاحة لاستثمار أموال الأوقاف ووجوب تنميتها. والمقصود بالاستثمار هنا توظيف أصول

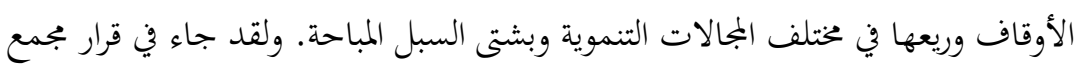
الفقه الإسلامي الدولي رقم 140 (15/6) بشأن الاستثمار في الوقف وفي غلاته وريعه: "يجب استثمار الأصول الوقفية، سواء أكانت عقارات أم منقولات، ما لم تكن موقوفة

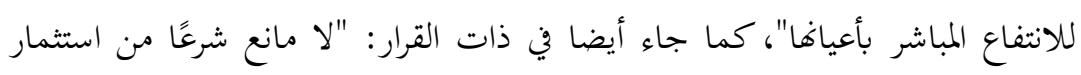

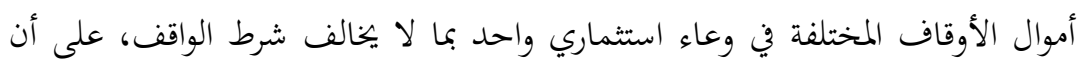
يحافظ على الذمم المستحقة للأوقاف عليها". 
نو تطوير نظام شبكي للوقف الإسلامي المتناهي الصغر

أما من الناحية السلوكية فإن نظام الأوقاف الصغرى يُسهم في بناء وتدعيم ثقافة الوقف لدى كل الفئات، وهو ما يعني تعزيز سلوك الوقف والتأثير إيجابيا في قرارات الإنفاق الخيري. ومن المستندات الشرعية الداعمة لبناء ثقافة الوقف الأصغر نكتفي بالإشارة إلى لي لئل الحديث النبوي الذي رواه أبو هريرة عن رسول الله -صلى الله عليه وسلم- أنه قال:

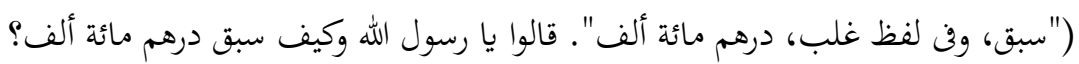
قال: "رجل له درهمان أخذ أحدهما فتصدق به، ورهم ورجله له له مال كال كثير فأخذ من عرَضه مائة ألف درهم فتصدق بها"). (النسائى، وأبو يعلى).

وفي هذا الإطار نشير أيضا إلى ما أصبح يعرف في الاقتصاد الغربي بالمالية السلوكية (Behavioral finance)، كفرع من فروع الاقتصاد السلوكي، والتي مؤداها أن قرار الإنفاق والاستثمار لا يخضع لقواعد العقلانية التقليدية، القائمة على منطق الرشد وتعظيم

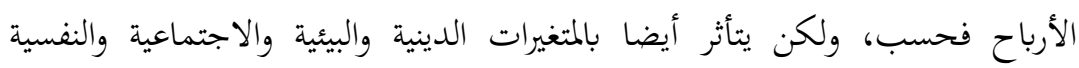
والعاطفية (الرشادة المحدودة)، والتي لا يمكن تفسير قرارات الأفراد بمعزل عنها. وفي هذا ولتها الإطار نشير إلى أن هناك عدة اقتصاديين حصلوا على جائزة نوبل نظير إسهاماقم في مجال الاقتصاد السلوكي والمالية السلوكية منهم: Richard Thaler (2017, Robert Shiller (2013), Joseph E. Stiglitz \& George Arthur Akerlof \& Michael كما نشير في هذا الصدد أيضا إلى البنغالي Spence (2001, Herbert Simon (1978) محمد يونس، مؤسس بنك غرامين للفقراء (Grameen Bank) ومهندس التمويل الأصغر، الذي تحصل جائزة نوبل للسلام في العام 2006 لأعماله حول المالية التضامنية

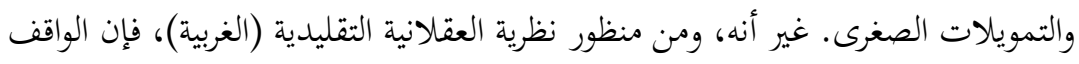

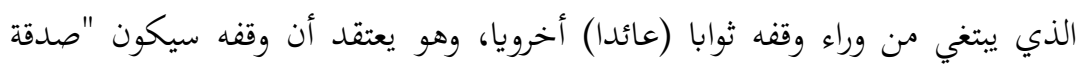
جارية"، لا يعتبر سلوكه هذا سلوكا اقتصاديا عقلانيا. وهكذا، فإن العائد المتوقع من الوقف الإسلامي، على خلاف الوقف في المنظور الغربي، ثلاثي الأبعاد: عائد اجتماعي، وعائد اقتصادي ومالي، وعائد أخروي. وهذا البعد إندان 
الأخير يمثل الهدف النهائي للمسلم، وهو نيل ثواب الآخرة، باعتبارها دار البقاء، بينما

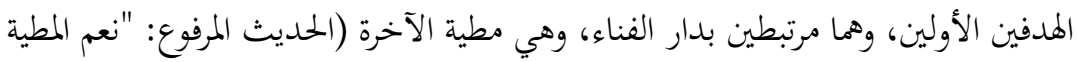
الدنيا، فارتحلوا تبلغكم الآخرة")، يعتبران هدفين وسيطين.

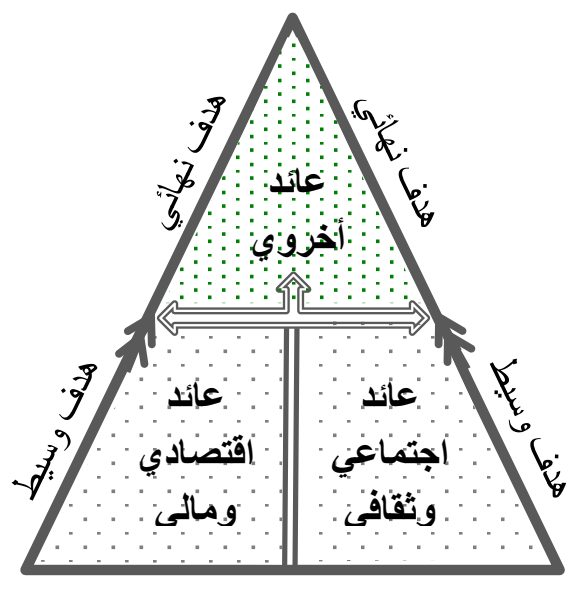

$$
\text { شكل (1): أبعاد العائد في الوقف الإسلامي }
$$

3- مرتكزات نظام الأوقاف الصغرى وآلياته:

يقوم نظام الوقف الأصغر على ثلاث ركائز: التنوع واللامركزية والإدماج. وهذه الركائز تنطوي على انعكاسات جد إيجابية على تنمية وعاء الأوقاف: (1) التنوع: من العوامل التي تنبثق منها أهمية الأوقاف الصغرى سمة التنوع التي تتميز بها، وهذا التنوع له أبعاد عديدة: ـ تنوع في فئات الواقفين: من حيث الدخل والجنس والعمر، وهو ما يعني ضمنا ارتفاع عدد الواقفين.

• تنوع في طبيعة الموقوفات: أوقاف نقدية وأوقاف عينية منقولة بمختلف طبائعها. ـ تنوع في الجهات القائمة: حيث نجد مؤسسات وصناديق وجمعيات وغيرها، وهذه الجهات قد تكون حكومية أو أهلية أو مشتركة. 
نحو تطوير نظام شبكي للوقف الإسلامي المتناهي الصغر

• تنوع في أدوات الوقف: النقد السائل، الشيكات، البطاقات البنكية، الصكوك

$$
\text { وشهادات الوقف، وغيرها. }
$$

• تنوع في الوسائل والوسائط المستخدمة: وتتضمن مختلف وسائل الإعلام والاتصال،

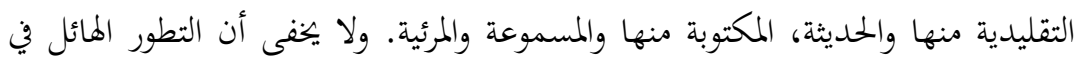

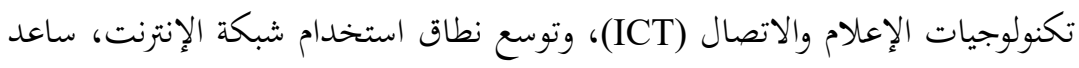
كثيرا في بروز وسائل وطرائق وآليات جديدة في بجال تعبئة الموارد الخيرية والوقفية (i-waqf) وحشد الواقفين، وخاصة منهم صغار الواقفين (أو الحشود)، ومن أبرزها الوقف الإلكتروني ومنصات التمويل الجماعي، التي أضحت نموذجا قائما بذاته، في إطار ما يعرف بالتمبن التمويل التكنولوجي (FinTech). للإشارة، يُميّز عادة في مجال التمويل الجماعي بين أربعة أنماط: تمويل جماعي قائم على الهبات، تمويل جماعي قائم على المكافآت (تشجيع المبادرات الخلاقة، خاصة ذات الطابع الاجتماعي)، تمويل جماعي قائم على الأسهم أو الأموال

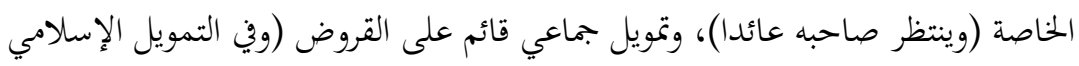

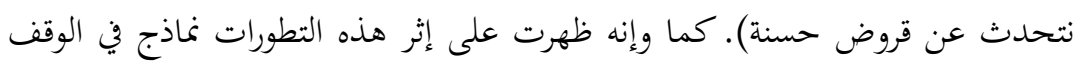
تعتمد على "نموذج قبول التكنولوجيا" (TAM : technology acceptance model)، والذي يهدف إلى دراسة سلوك الأفراد نخو استخدام التكنولوجيا بخصوص ظاهرة معينة. ولقد قدمت دراسات على أساس هذه المقاربة في مجال الوقف (Thaker et al., 2018). (2) اللامركزية والمحلية: من المقومات الأساسية لتحقيق الفعالية في أنظمة الأوقاف الصغرى الانتشار الجغرافي الواسع للهيئات والصناديق التي تعنى بالأوقاف الصغرى محليا،

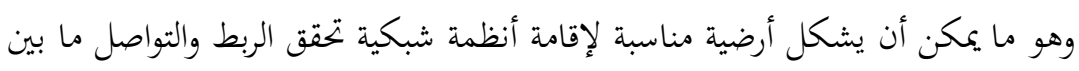

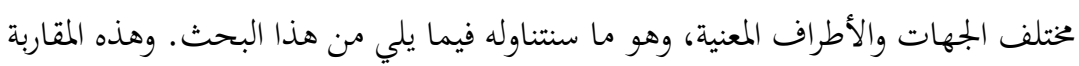

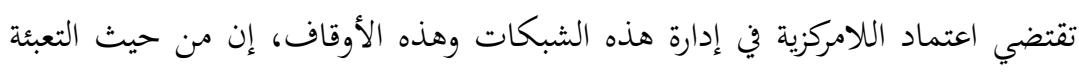

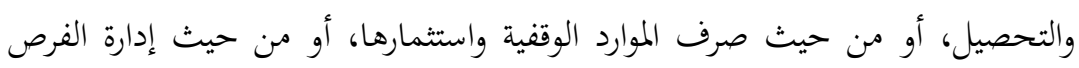
وتبادل الخبرات والاستشارات ما بين الأطراف العاملة في الميدان. 
(3) الإدماج: والمقصود به، ليس فحسب إدماج كل فئات المجتمع في الفعل الوقفي

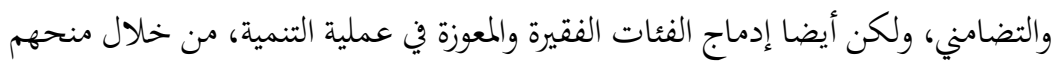
فرصا تمويلية لإنشاء مشاريعهم الاستثمارية، وتحويلهم من فقراء ومتسولين إلى مستثمرين

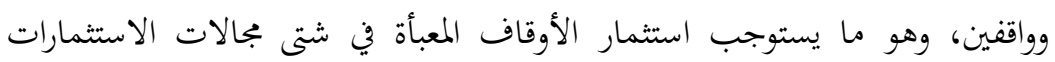

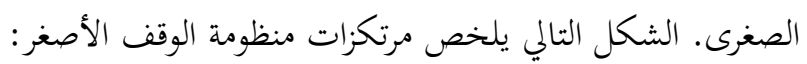

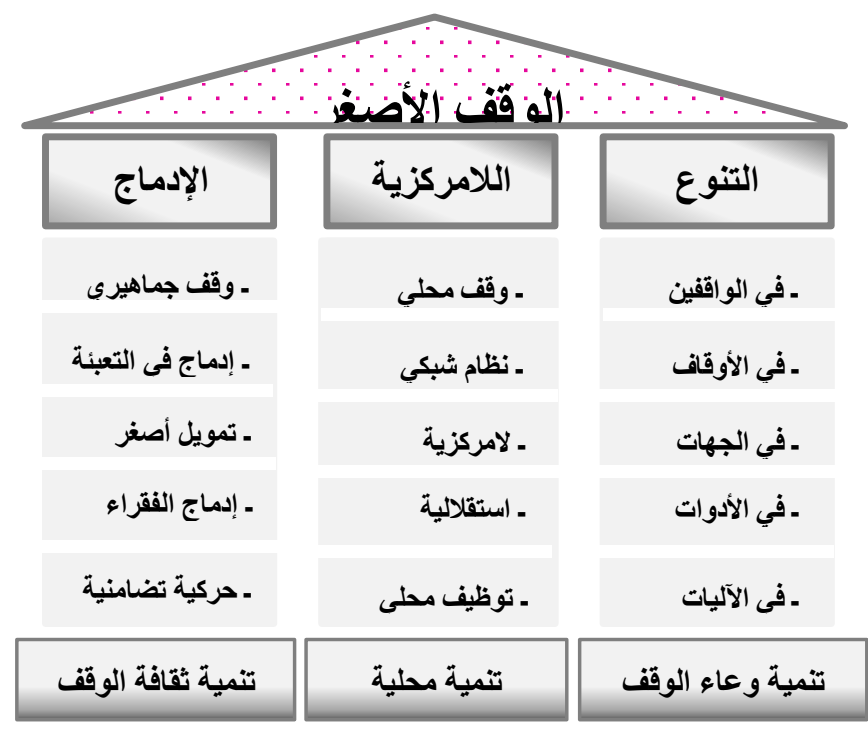

$$
\text { شكل (2): (2) مرتكزات نظام الوقف الأصغر }
$$

ثمة آليات وأدوات عديدة ومتنوعة تتجسد من خلالما ممارسة الأوقاف الصغرى: الآليات: وهي تضمن مختلف الهياكل الأساسية لعمل النظام، من أبرزها:

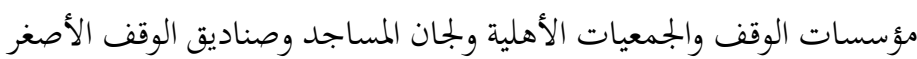
وبنوك الوقف (بنوك الوقف المقصودة في هذا المقترح هي تلك المتخصصة في تمويل المشروعات الصغرى على سبيل التضامن والتعاون، ولو تضمنت 
نغو تطوير نظام شبكي للوقف الإسلامي المتناهي الصغر

تمويلاتحا عائدا مقبولا بغرض تنمية الأوقاف ودفع المستفيدين على العمل

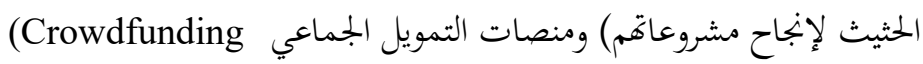
(Platform)

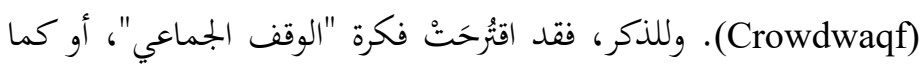

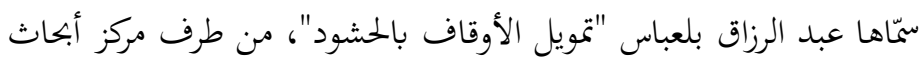

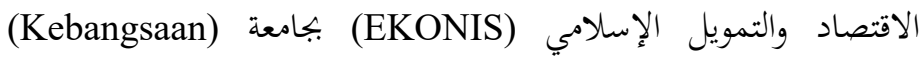
بماليزيا، وذلك في إطار مائدة حوار نظمها المعهد الإسلامي للبحوث والتدريب بجدة في 21 يناير 2016. وفي 3 أغسطس 2016 تم إطلاق أول منصة رقمية للوقف الجماعي (waqfworld.org) بجكرتا (بلعباس، 2016). ولكن أيضا هناك هياكل داعمة للنظام، على غرار وزارات الأوقاف ومديرياتا الجهوية، من خلال وصايتها وإشرافها وتنظيمها للعمل الوقفي، وكذا المساجد والمعاهد الدينية، من خلال سندها الفقهي والتوعوي، ونها وحتى بعض المواقع المتخصصة على شبكة الإنترنت، وغير ذلك من الجهات التي تُسهم في دعم نظام الوقف عموما، والوقف الأصغر على وجه الخصوص.

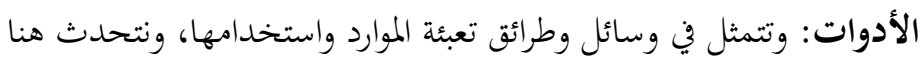
عن النقد (العادي والإلكتروني) وصكوك الوقف وشهادات الوقف وكل وسيلة لتحويل الأموال. وعلى سبيل المثال اقترح أنور بيتشاي وآخرون، في إطار دراسة حول سلوك الموظفين نحو الوقف النقدي، أسلوب الاقتطاع المباشر

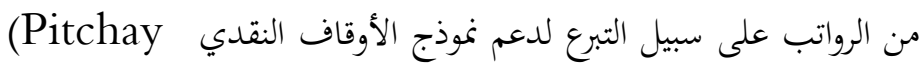
et al., 2015, pp 57-9) المحمولة للغرض ذاته. ومن جهة أخرى تشمل هذه الأدوات أيضا طرق الإنفاق وصيغ التمويل الإسلامي المناسبة لكل استخدام (تمويل المشروعات الصغرى)، على غرار المرابحة والمضاربة والمشاركة المؤقتة. 
يمكن تلخيص الإطار العام لنظام الوقف الأصغر وآليات عمله من خلال المخطط

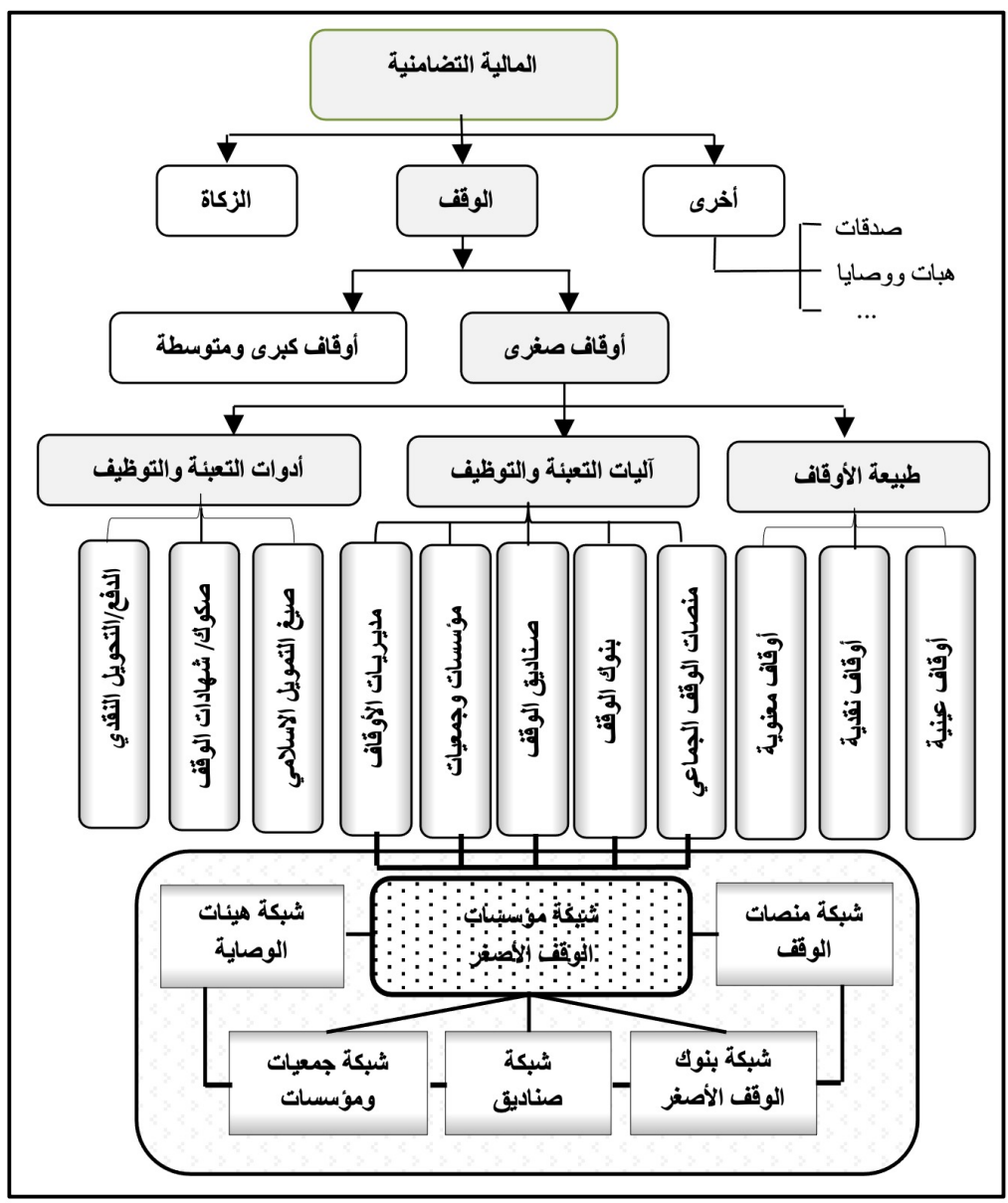

شكل (3): إطار الوقف الأصغر، آلياته وأدواته ونظامه الشبكي 
نغو تطوير نظام شبكي للوقف الإسلامي المتناهي الصغر

غير أنه، وعلى الرغم من هذا التنوع في الآليات والأدوات المستحدثة، على غرار بنوك الوقف ومنصات التمويل الجماعي وصكوك الوقف وأدوات التحويل المالي الإلكتروين وغيرها، وهو ما يعد تطورا لافتا في مسار الإدارة الوقفية، يتعين ضبط هذه المستحدثات بما يضمن حماية روح الوقف ووظيفته الأساسية، ومن ثم تفادي أية انزلاقات محتملة، سواء أكانت شرعية أم وظيفية، قد تُفضي في هاية المطاف إلى تفريغ الوقف من مضامينه الأصلية، وتحويل مؤسسات الوقف إلى مجرد هياكل تمويلية يهكمها منطق السوق، وتميمن

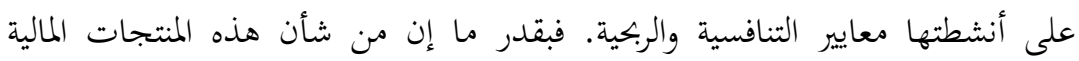
المستحدثة أن تساعد في تطوير نشاط الوقف وتوسيع نطاقه والدفع به قدما، بقدر ما يمكن أن تتولد عنها مخاطر قد تعصف بتلك النوايا الحسنة التي كانت وراء ابتكارها.

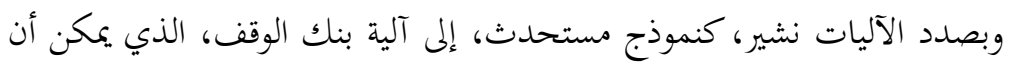

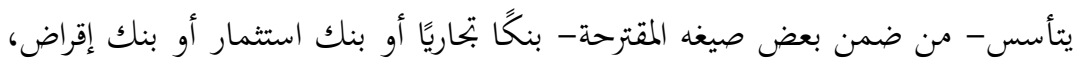

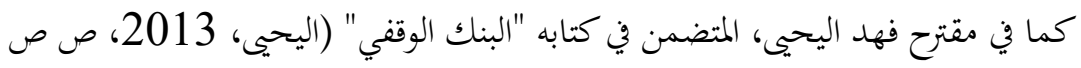

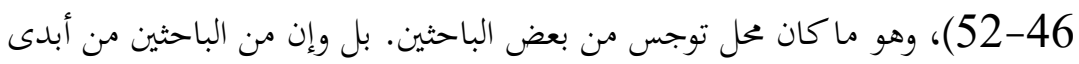

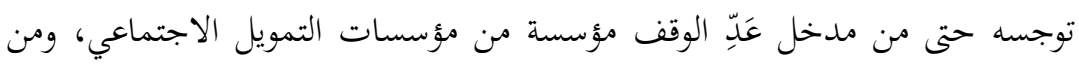

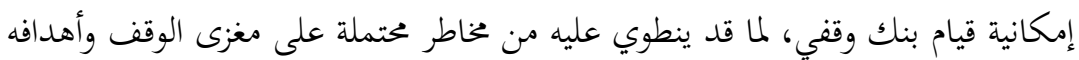
الاجتماعية (بلوافي، 2010).

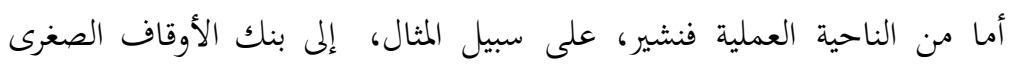
بإندونيسيا، الذي أطلقته الحكومة وسلطة ضبط الخدمات المالية (OJK) في نوفمبر

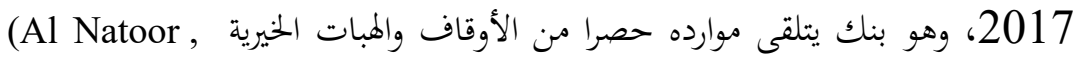
2018, p66) وكذا منصات التمويل الجماعي، القائمة على أساس أحكام التمويل الإسلامي، التي أخذت في الانتشار في عدد من البلدان الإسلامية، كما في إندونيسيا وماليزيا

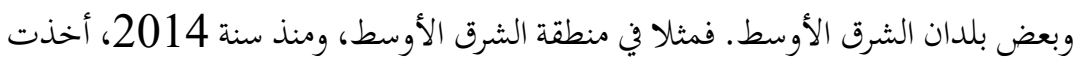
منصات التمويل الجماعي الإسلامي في التزايد، حيث بلغت نهو 10 منصات موزعة 
بالمنطقة ( 2018 Bahrain FinTech Ecosystem Report). وجدير بالذكر هنا أن من الأغراض الأساسية لمذه المنصات تمويل المشروعات الصغرى في إطار المالية التضامنية. 4- الصياغة البيانية والرياضية للوقف الأصغر:

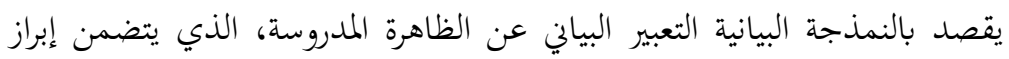

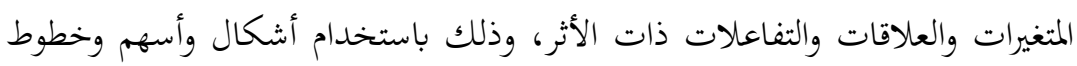
ورموز بحيث يحمل كل منها دلالة معينة وواضحة. ويسمح مثل هذا التمثيل البياني بفهم

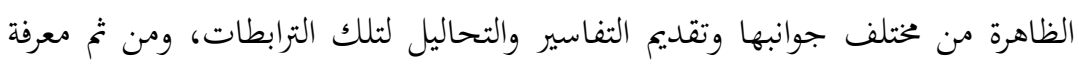
مواطن الخلل والعمل على اقتراح علاج هلا. وبالموازاة، تدل النمذجة الرياضية على تمثيل

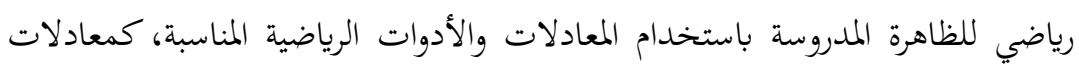
التفاضل والتكامل واللوغاريتم وغيرها. فالنموذج إذا هو عبارة عن محاكاة للظاهرة وتمثيلا

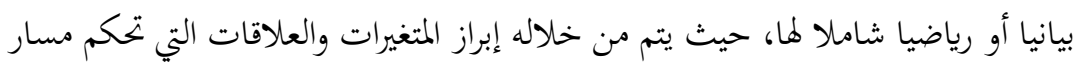
الظاهرة.

إن أية نمذجة للوقف، سواء أكانت بيانية أم رياضية، تستدعي ضبط ثلاثة عناصر

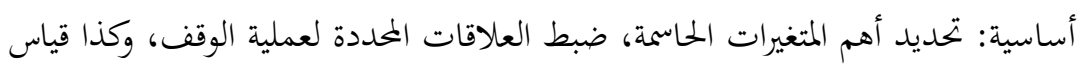

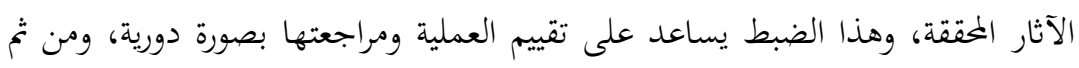

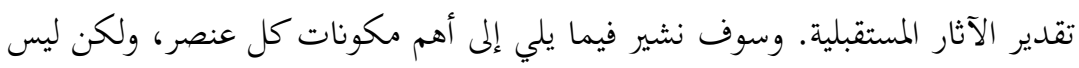

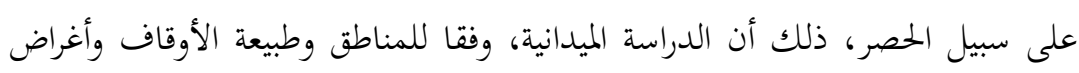

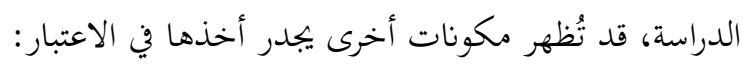
() تحديد المثغيرات: مع أن المتغيرات التي تتحكم في ظاهرة الوقف عديدة لخدهات ومتنوعة، كغيرها من الظواهر، فمنها: الظاهرة والخفية، ومنها: المباشرة وغير المباشرة، ومنها:

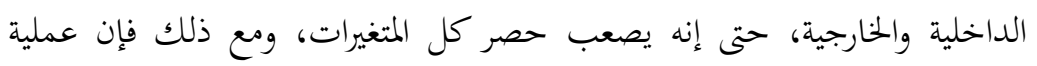

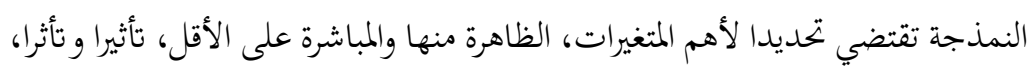
حتى يمكن صياغة المعادلات الأساسية. ومن ضمن هذه المتغيرات نذكر على وجهات الماتهره 
نحو تطوير نظام شبكي للوقف الإسلامي المتناهي الصغر

الخصوص: عدد الواقفين خلال فترة زمنية محددة؛ طبيعة الأوقاف؛ حجم الوقف

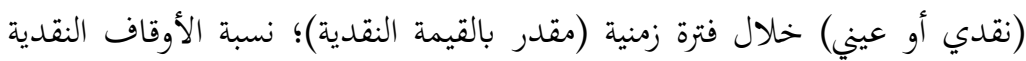
بالنسبة إلى الأوقاف العينية؛ عدد هياكل الوقف المؤسسي (مثلا عدد الصناديق في حالة دراسة نموذج صناديق الوقف الأصغر)؛ إلخ. 2 ضبط العلاقات: وتشمل كافة العلاقات التعاقدية المرتبطة بالأموال الوقفية: العلاقة

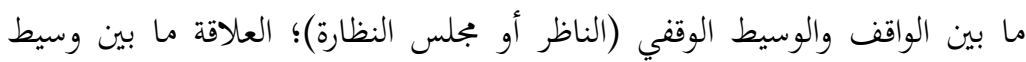
الوقف والموقوف عليهم (قرض حسن، تمويل، ...)؛ شرط (شروط) الواقف؛ أدوات

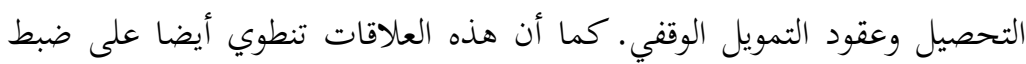
مختلف التدفقات من حيث طبيعتها (نقدية/عينية) وحجمها (تقدير نقدي) واتحاهها (تدفقات داخلة/تدفقات خارجة).

3 قياس الآثار: وهذا القياس يستوجب وضع مؤشرات، كمية ونوعية، تتسم بالموضوعية والشمولية. وتنصب هذه الآثار على: الموقوف عليهم؛ حصيلة الأوقاف؛ التنمية المحلية (تنمية بشرية، اقتصادية، اجتماعية وثقافية). وحتى يكون القياس ذا معنى ينبغي

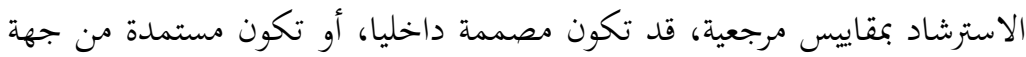

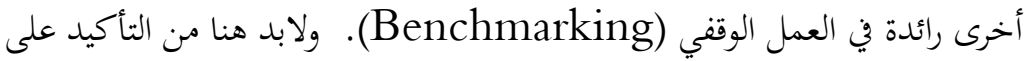
أن عملية القياس هذه ذات هدف مزدوج: تقويم أعمال هيكل الوقف من ناحية، ووضع خطة عمل مستقبلية (خخطط عمل أو مخطط تنمية)، تتضمن موازنة تقديرية (الجانب المالي) وبجالات النشاط ذات الأولوية وذات الأثر القوي على التنمية المحلية

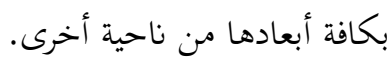

سوف نستند في عملية نمذجة الوقف الأصغر، بيانيا ورياضيا، إلى مجموعة من

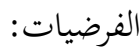

الأوقاف الصغرى تقوم على قانون الأعداد الكبيرة: فمع أن هذا القانون يرتبط أصلا بفيزياء الكم، فإن استخداماته امتدت إلى مختلف المجالات، بما في ذلك الك المالية. 
ونستوحي منه، في مجال الوقف الأصغر، أن الأعداد الكبيرة للأوقاف وللواقفين ينتج عنه نموا مطردا في حصيلة الأوقاف. الأوقاف الصغرى تندرج ضمن "الوقف المشترك"، حيث يشترك في الوقف عدد كبير

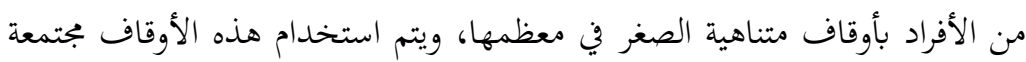
من قبل الجههة المستقبلة لما. لا مانع شرعاً من استثمار أموال الأوقاف المختلفة في وعاء استثماري واحد بما لا لا مئل يخالف شرط الواقف. الوقف الأصغر دالة مستمرة: إذ إن عملية الوقف الأصغر تتسم بالاستمرارية في الزمن،

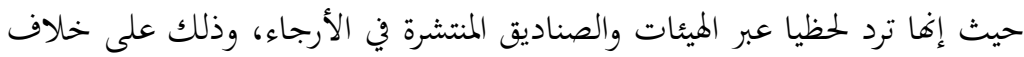
الأوقاف الكبرى، التي لا تتمتع بهذه الصفة. الوقف الأصغر متغير عشوائي: إذ إن قيم الأوقاف الصغرى التي يتم تحصيلها خلال

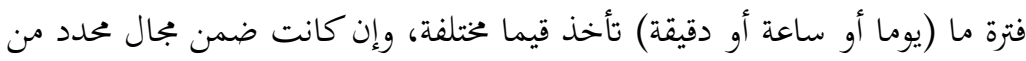
القيم، باعتبار الحد الأقصى المحدد للوقف الأصغر.

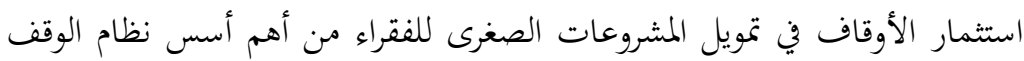
الأصغر، وهو يمثل هدفا مركزيا لهذا النظام.

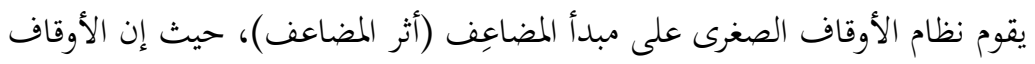
الصغرى تولد تمويلات للمشروعات الصغرى، وهذه الأخيرة تولد أوقافا، والتي بدورها

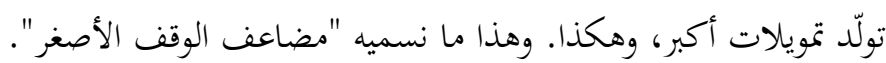
نظام الوقف الأصغر المقترح نظام شبكي: وهذا يعني أن هناك تبادلا للمعلومات وهات والخبرات ما بين عناصر هذا النظام، كما أن هناك تدفقات للأموال الوقفية (لاسيما الفائض الوقفي) ما بين مختلف الهياكل في المنطقة ذاتا وخارجها، مع مراعاة الفرضية 
نغو تطوير نظام شبكي للوقف الإسلامي المتناهي الصغر

هأساس نظام الوقف الأصغر هو المحلية، أي: إن الأولوية في استخدام موارد الأوقاف

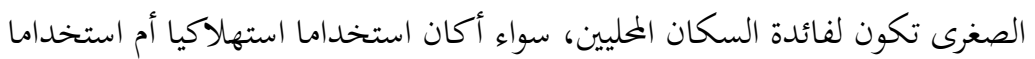
استثماريا.

إن هذه الفرضيات تشكل دليلا لعملية النمذجة، منها ما يتعلق بصورة أكبر بالنمذجة البيانية، ومنها ما يرتبط بالنمذجة والصياغة الرياضية، ولو أن هناك تداخلا للفرضيات في النمذجتين. وفيما يلي، نحاول تمثيل نموذج الوقف الأصغر بيانيا من خلال أشكال ومخططات، ورياضيا: من خلال استخدام بعض المعادلات. المخطط التالي عبارة عن تمثيل بياني لنموذج مبسط لنظام الوقف الأصغر:

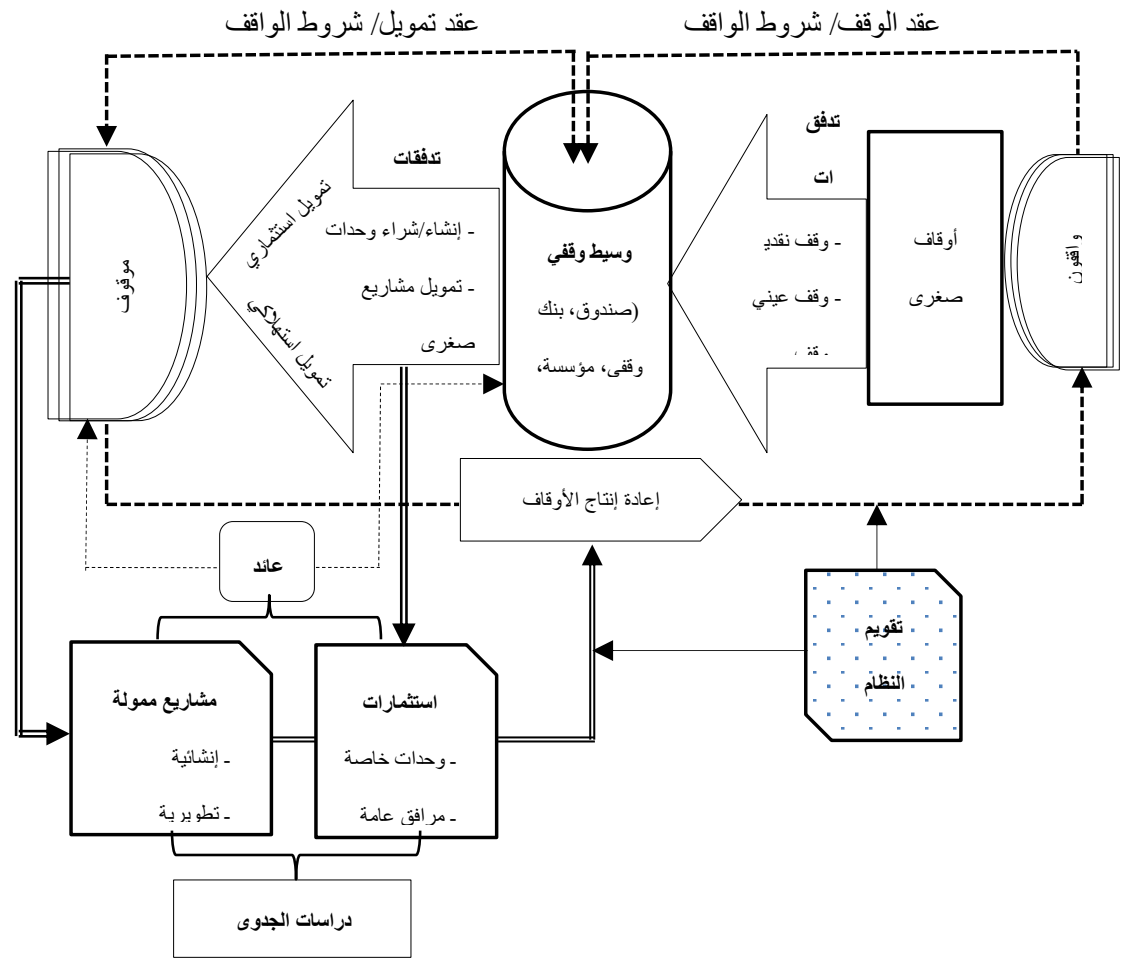

شكل (4): نموذج مبسط لنظام الأوقاف الصغرى 
ثمة توضيحات لابد منها بخصوص بعض العناصر الواردة في هذا الشكل (شكل رقم

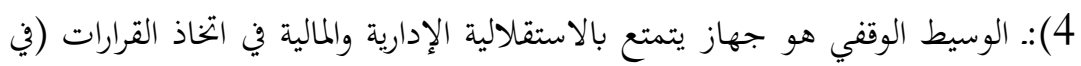

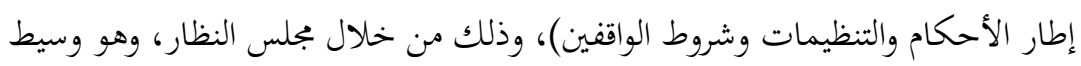

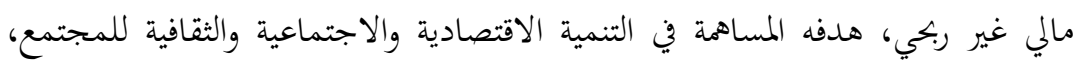
لاسيما المحلي منه على وجه الخصوص. وفي الغالب تلكون أجهزة الأوقاف تحت وصاية

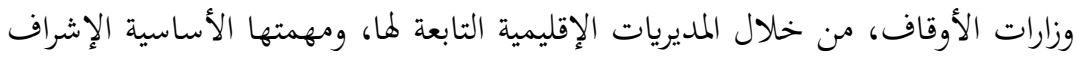
والرقابة، هذا إلى جانب الرقابة القضائية على أعمال النظار، التي قررها عدد من الفقهاء المعاصرين، وفقا للمعيار الشرعي رقم 33 لهيئة المحاسبة والمراجعة للمؤسسات الماتئل المالية الإسلامية أيوفي (اليحيى، وففعاصيار 2013).

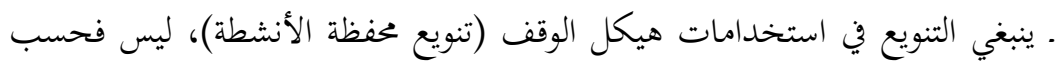
توزيعا للمخاطر، ولكن أساسا لتغطية أوسع نطاق من الأهداف، مع مراعاة مبدأ

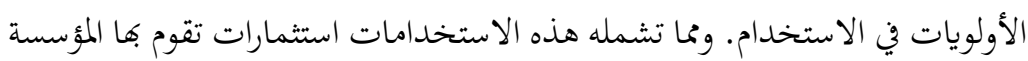

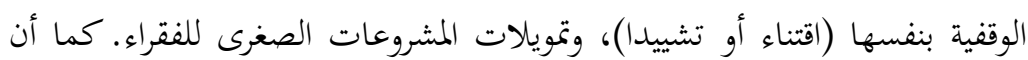

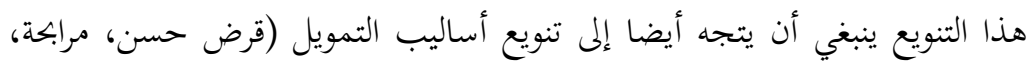
استصناع، إجارة منتهية بالتمليك، ل...). ـ العائد الذي يطلبه هيكل الوقف (مؤسسة، صندوق، ...) من تمويلاته للمشاريع

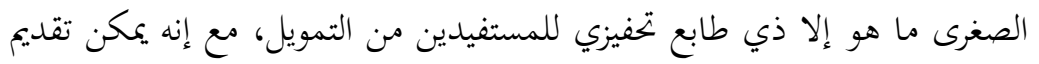

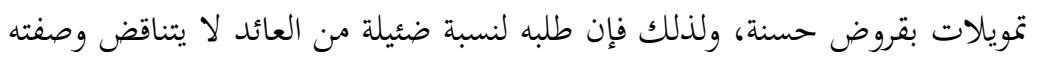
غير الربحية. فاستخدام مصطلح العائد لا يعني بأية حال السقوط في فخ تحول هول جهاز

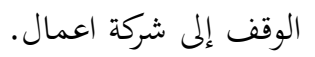


نحو تطوير نظام شبكي للوقف الإسلامي المتناهي الصغر

ـ تقويم النظام ينبغي أن يتسم بالشمولية، وهو عملية تستهدف مراجعة مواطن الخلل

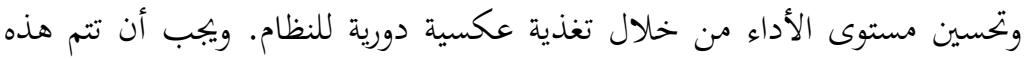

العملية على أساس مجموعة من المعايير المرجعية، مع مراعاة الدقة والموضوعية.

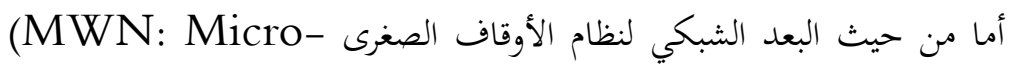

Waqf Network) مبدأي: التعاون (Cooperation) والتعاضد أو التآزر (Synergy)، تحكمها بعابه

تنظيمات واتفاقيات، فيمكن تمثيل ذلك من خلال المخطط التالي:

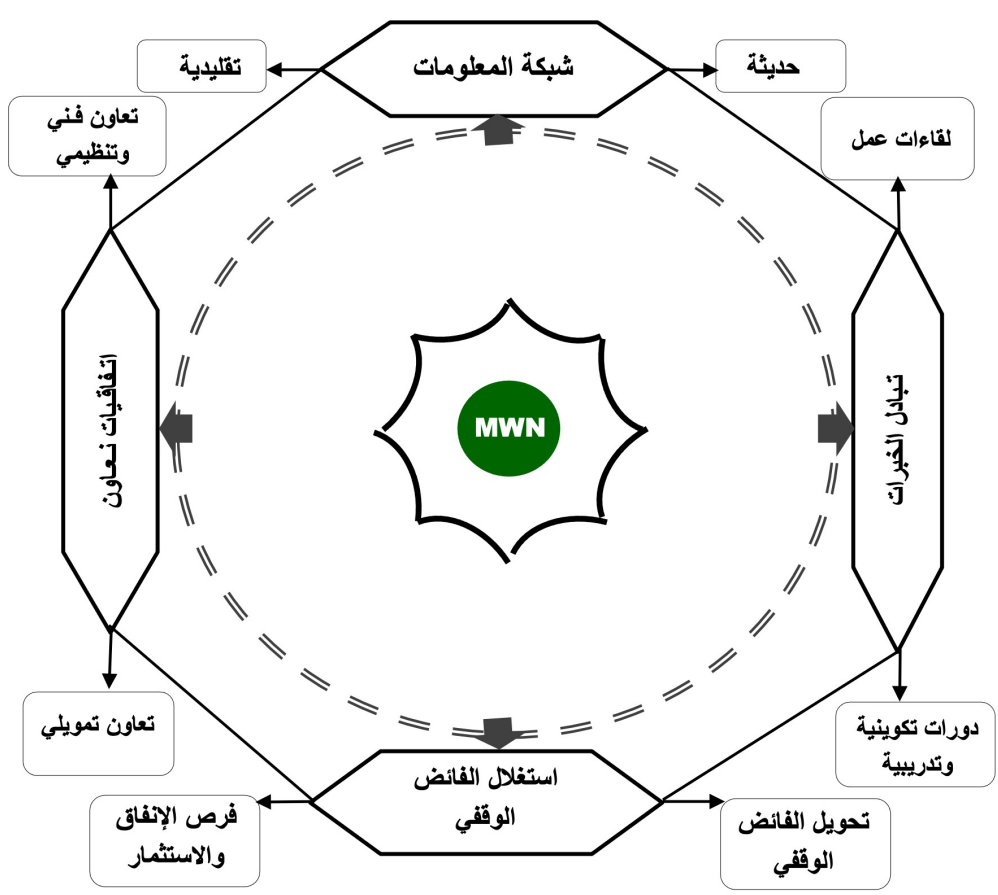

شكل (5): شبكة مؤسسات الوقف الأصغر 
يمكن أن تتشكل شبكات متعددة لياكل الوقف الأصغر حسب طبيعة هذه الهياكل، ومن خلال ربط هذه الشبكات الفرعية تتشكل شبكة متكاملة (أو مدبجة) للأوقاف

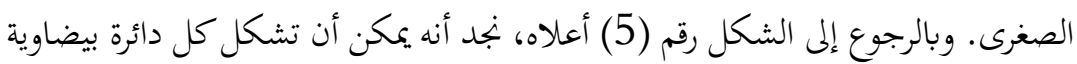

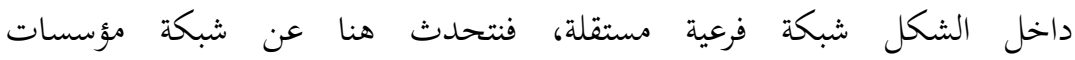
(Foundations) الوقف الأصغر، شبكة منصات التمويل الوقفي الأصغر، شبكة بنوك الوقف الأصغر، وهكذا.

إنه وعلى الرغم من أهمية النمذجة البيانية في تمثيل الظواهر وإبراز أهم العلاقات ما

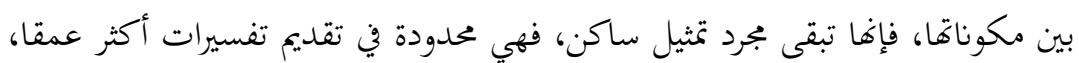

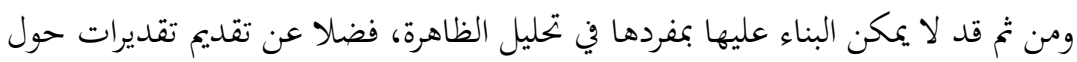

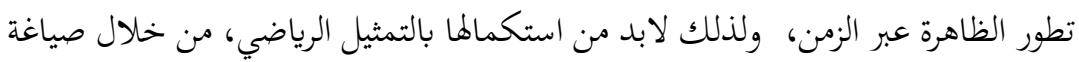
تلك العلاقات في صورة معادلات. إذا انطلقنا من معادلة الإنفاق العام المتمثلة في أن الدخل Y موزع بئ بين الاستهلاك والادخار S، أي philanthropy) $p$ هو جزء بـ الادخار S، والجزء الآخر S موزع بين الاستثمار الربحي والاحتياط، فإنه يمكن كتابة:

$$
\begin{aligned}
& y=C+(s+p) \\
& \text { إذا كانت نسبة الميل إلى الاستهلاك هي } \alpha \text { فإن: } \\
& y=\alpha y+(1-\alpha)(s+p) \\
& y=\alpha y+(1-\alpha) s+(1-\alpha) p \\
& (1-\alpha) p=y-\alpha y-(1-\alpha) s \\
& (1-\alpha) p \\
& =(1-\alpha) y-(1-\alpha) s
\end{aligned}
$$

وكما ذكرنا فإن الإنفاق الخيري p مكون من الأوقاف والصدقات والهبات وغيرها. فإذا

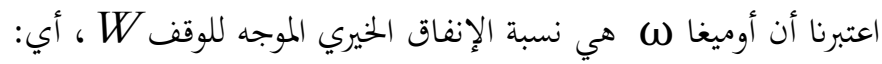


غو تطوير نظام شبكي للوقف الإساهي المتناهي الصغر

$$
\begin{gathered}
W=\omega p \Leftrightarrow p=\frac{W}{\omega} \\
(1-a) \frac{W}{\omega}=(1-a) y-(1-a) s \\
\frac{W}{\omega}=\frac{(1-a) y-(1-a) s}{(1-a)} \\
\omega=\frac{(1-a) W}{(1-a) y-(1-a) s} \\
\omega=\frac{(1-a) W}{(1-a)(y-s)} \\
\omega=W \frac{1}{y-s} \cdots \cdots \cdots \cdots(2)
\end{gathered}
$$

وبالتالي فإن الميل إلى الوقف يساوي:

وإذا قسمنا الأوقاف W إلى أوقاف صغرى W

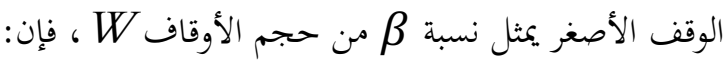

$$
\begin{gathered}
W_{L}=\beta W \Leftrightarrow W=\frac{W_{L}}{\beta} \\
\omega=\frac{W_{L}}{\beta} \frac{1}{y-s}=\frac{W_{L}}{\beta(y-s)} \\
W_{L}=\omega \beta(y-s) \\
\beta=\frac{W_{L}}{\omega(y-s)}=W_{L} \frac{1}{\omega(y-s)}
\end{gathered}
$$

يلاحظ أن حجم الأوقاف الصغرى يساوي إلى (s-

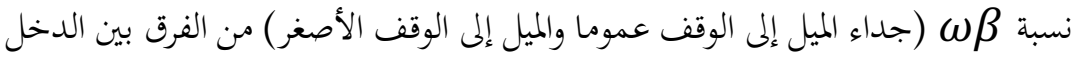

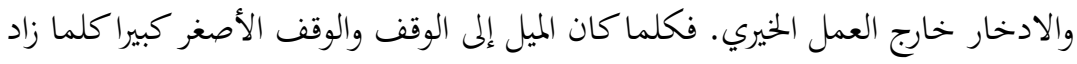


حجم الأوقاف الصغرى. أما الميل إلى الوقف الأصغر $\beta$ فيساوي وهذا يعني أنه كلما كان الفرق (S-S) ضئيلا، وبالتالي يكون الإنفاق الموجه للعمل الخيري p كبيرا، كلما زاد حجم الأوقاف الصغرى، إذ إن الإنفاق الخيري هو ما يتبقى من الدخل بعد الاستهلاك C والادخار الموجه للاستثمار الربحي 5. تجدر الإشارة إلى أن الميل إلى الوقف يعد من أبرز المتغيرات التي يخضع إليها

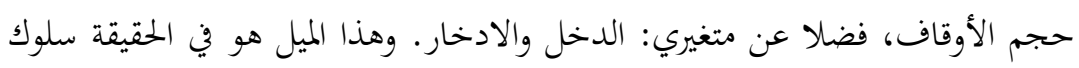

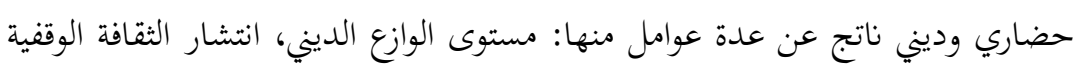
والثقافة التضامنية عموما، جهود هيئات الوقف ومختلف الهيئات المعنية بالنشاط التضامني والخيري، درجة تطور الآليات والأدوات الخاصة بتعبئة الأوقاف وغيرها. فالسلوك الوقفي إذاً هو بناء تشارك فيه أطراف عديدة، بما فيها وسائل الإعلام وهيئات المجتمع المدني والأفراد، ناهيك عن المؤسسات ذات الصلة. ومن ناحية أخرى نشير إلى أن الميل إلى الوقف ف والميل إلى الوقف الأصغر

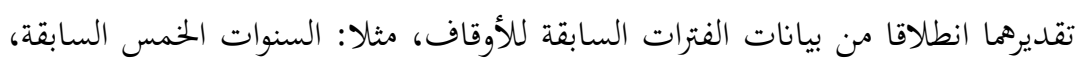
وهو ما يقتضي إقامة نظام وطني للمعلومات الوقفية، الذي يعد نظاما بالغ الأهمية لمتابعة كل الجوانب المتعلقة بالنشاط الوقفي، وربما يمكن توسيعه إلى نظام وطني للمالية التضامنية، لتشمل أيضا الزكاة وغيرها من التدفقات المالية التضامنية. والواقع أن هذه المتابعة تتم حاليا في جل الدول الإسلامية عبر مديريات، وبطريقة غير متطورة، حتى إنه لا تستطيع تقديم

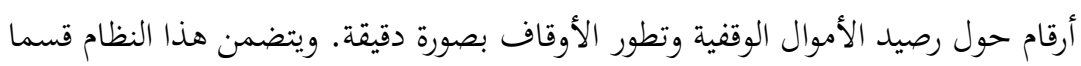

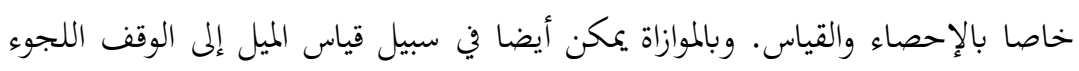
إلى أسلوب الاستقصاء الموسع يشمل مختلف فئات المجتمع.

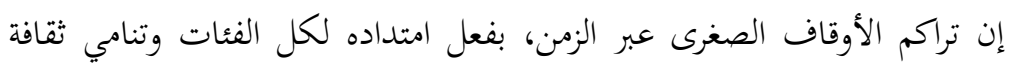

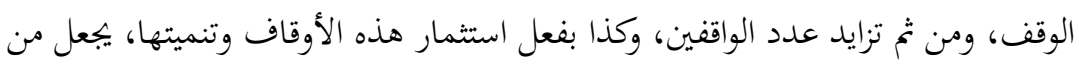

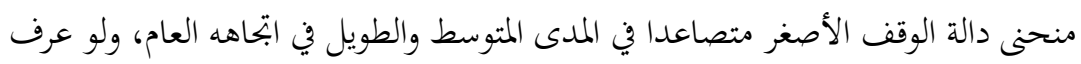


نحو تطوير نظام شبكي للوقف الإسلامي المتناهي الصغر

انخفاضا في بعض الفترات، كما أن كل مرحلة في بناء نظام الأوقاف الصغرى لها متطلباتها

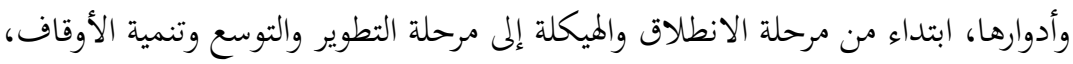
وإلى مرحلة إقامة نظام شبكي للأوقاف. يمكن توضيح ذلك من خلال الشكل التالي:

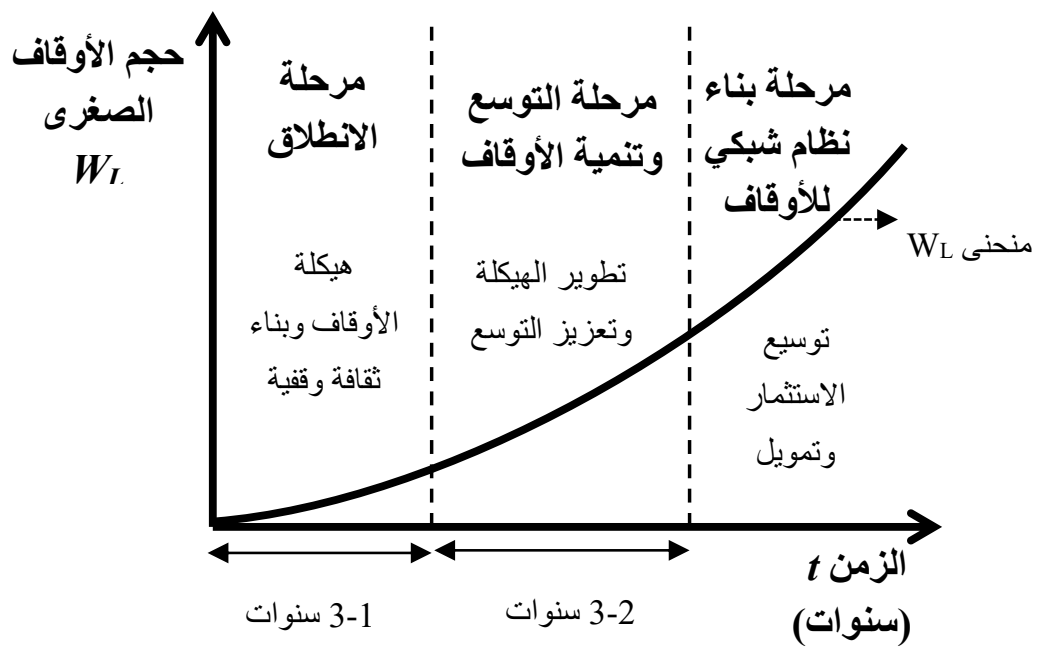

شكل (6): تطور الأوقاف الصغرى عبر الزمن ومراحل إقامة نظام شبكي للوقف الأصغر

إن بناء نظام متين ومتماسك للأوقاف الصغرى يتطلب وقتا وجهدا في إطار خطة مدروسة، ويتطلب إشراك عدة أطرف في هذا البناء، ولكن لابد من وجود إطار فقهي وتشريعي داعم لهذا المسار ـ وتختلف فترة تحقيق كل مرحلة من مراحله من مجتمع إلى آخر،

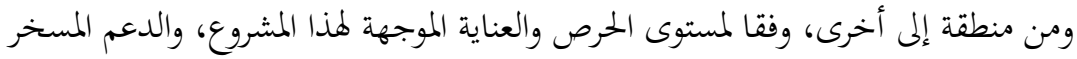
له، والتسهيلات والتحفيزات الضرورية من الجهات الحكومية (التسهيلات الإدارية 
والإعفاءات أو التخفيضات الضريبية لمؤسسات الوقف). فمثلا مرحلة الانطلاق، وهي أصعب المراحل، قد تستغرق سنة وقد تستغرق ثلاث سنوات.

يعبر منحنى الأوقاف الصغرى، بشكليها: النقدي (cash waqf) والعيني (kind waqf) (العن هدف تعظيم حصيلة الأوقاف، وهي "دالة الهدف" للقائمين

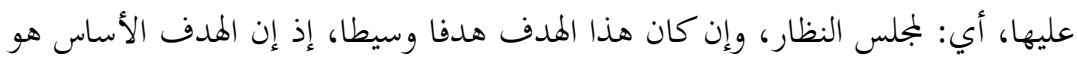
المساهمة في التنمية الاجتماعية والاقتصادية للمجتمع. غير أن تحقيق ذلك يقتضي إيجاد موارد كافية، أي تحقيق نماء في الموارد الوقفية. وكما ذكرنا فإن هذه الأوقاف تتكون من أوقاف نقدية وأخرى عينية، والأوقاف العينية مختلفة الطبيعة، وهي أوقاف مستمرة في الزمن، ولذلك لابد من متابعة محاسبية مستمرة من خلال إدارة خاصة. ومن الأدوات

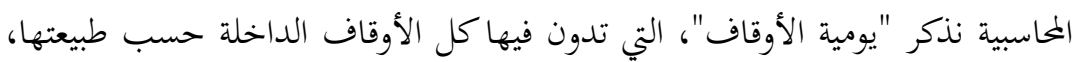
مع تقدير قيمتها نقديا. فإذا قسمنا هذه الأوقاف العينية الصغرى إلى m فئة، حيث كل فئة تضم بجموعة متجانسة من الأوقاف (عتاد فلاحي، عتاد إلكتروبن، معدات بناء،

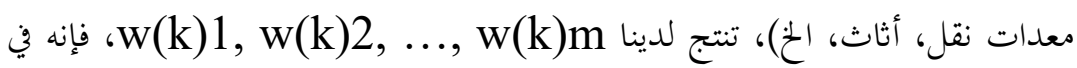

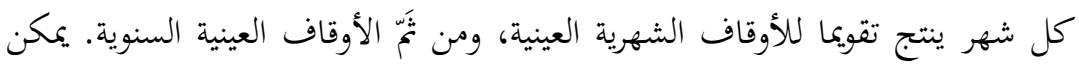
توضيح ذلك من خلال الجدول التالي:

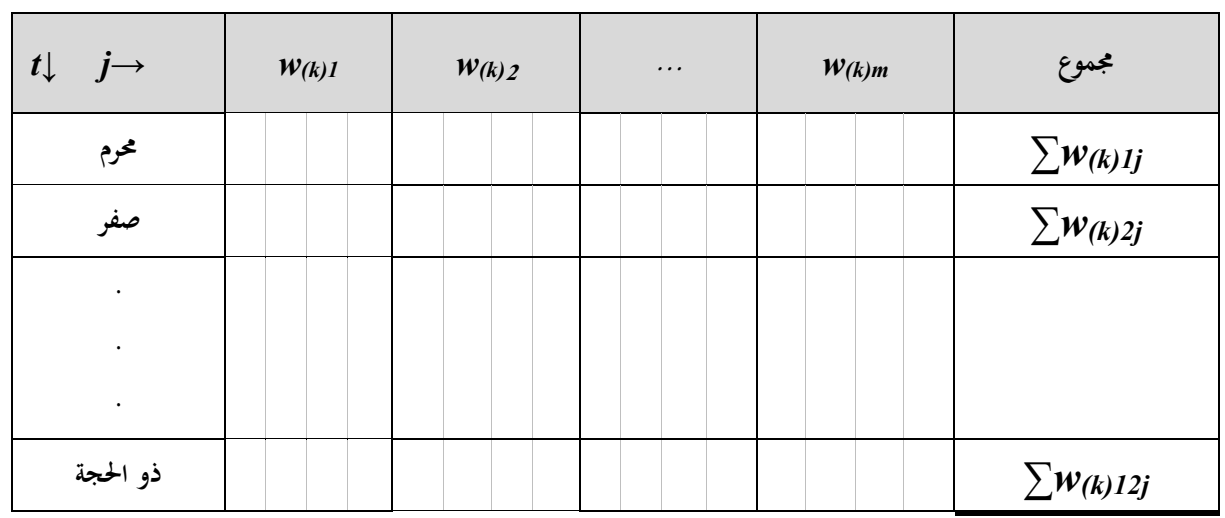


نغو تطوير نظام شبكي للوقف الإسلامي المتناهي الصغر

\begin{tabular}{|c|c|c|c|c|c|c|}
\hline 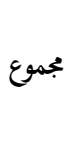 & $\sum w_{(k) 1 t}$ & $\sum w_{(k) 2 t}$ & $\ldots$ & $\sum w_{(k) m t}$ & $\sum_{t=1}^{12} \sum_{j=1}^{m}$ & $w_{(k) t j}$ \\
\hline \multicolumn{7}{|c|}{ الحصيلة السنوية للأوقاف العينية الصغرى (k) } \\
\hline
\end{tabular}

جدول (1): حساب الحصيلة السنوية للأوقاف العينية الصغرى

أما بالنسبة للأوقاف النقدية الصغرى، وهي ذات طبيعة واحدة، فيستحسن حسابها حسب الأيام والأسابيع، فالشهر والسنة، كما هو مبين في الجدول التالي:

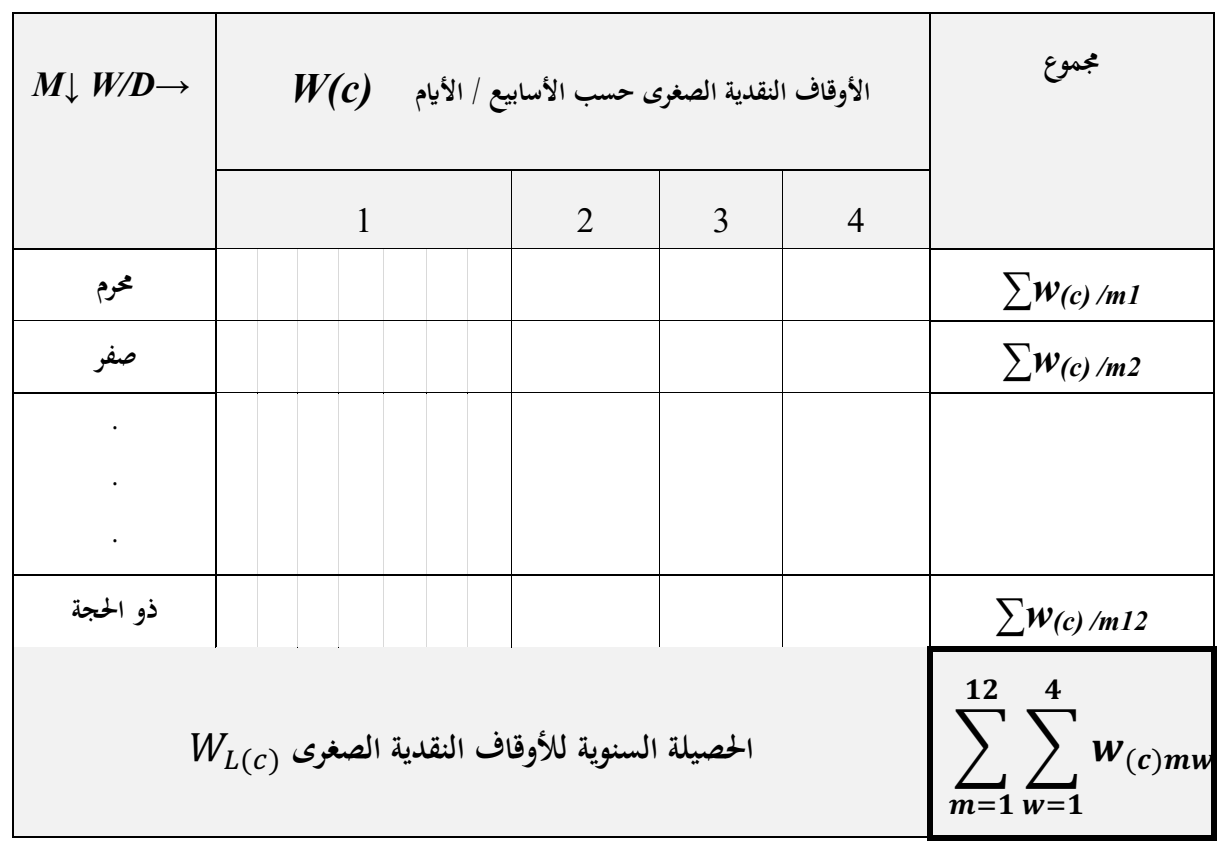

جدول (2): حساب الحصيلة السنوية للأوقاف النقدية الصغرى 
إذا ما عبرنا عن الأوقاف العينية WL(k) بصورة نقدية، وتم دججها مع الأوقاف النقدية (c)

$$
\operatorname{Max}_{\left(t_{0} \cdots t_{n}\right)} W_{L}(t)=W_{L(c)}+W_{L(k)}
$$

$$
\begin{aligned}
& \operatorname{Max}_{\left(t_{0} \cdots t_{n}\right)} W_{L}(t)=\operatorname{Max}_{\left(t_{0} \cdots t_{n}\right)}\left(\sum_{t=1}^{n} \sum_{j=1}^{m} w_{L(k) t j}+\sum_{\boldsymbol{m}=\mathbf{1}}^{12} \sum_{\boldsymbol{w}=\mathbf{1}}^{\mathbf{4}} \boldsymbol{w}_{(\boldsymbol{c}) \boldsymbol{m} \boldsymbol{w}}\right) \\
& 0 \& w_{L(c) m w} \geq 0 \\
& w_{L(k) j t} \geq
\end{aligned}
$$

إن هدف تعظيم حصيلة الأوقاف الصغرى يستدعي بذل جهود على أساس برنامج عمل، يتم بجسيده وفق تنظيم محكم، مزود بإمكانيات كافية وأدوات متنوعة ومرنة لتعبئة الأوقاف. ولا يخفى أن هذا البرنامج يخضع لمجموعة من القيود والتحديات، منها: الضوابط الشرعية، وعلى رأسها شروط الواقفين، ومقتضى عقد الوقف، وأحكام استثمار الأموال الوقفية، ومنها: الضوابط والقيود الاقتصادية والاجتماعية، كضرورة مراعاة الأولويات، على ضوء مقاصد الشريعة الإسلامية والمتطلبات المحلية، والقيام بدراسات الجدوى للمشروعات المرشحة للتمويل وغيرها، ومنها: التحديات الثقافية، المنبثقة بالأساس عن تدني مستوى الوعي الوقفي لدى عموم الأفراد، ومنها أيضا تحديات وقيود قانونية، يفرضها واقع التشريع المتعلق بالأوقاف. وإلى جانب ذلك، هناك قيودٌ تتعلق بالحصائل المقدرة للأوقاف الصغرى، التي يجب على القائمين تحقيقها خلال كل فترة، وهذه التقديرات (الخاصة بكل فترة) يتم وضعها مسبقا في برنامج العمل، وهي في حد ذاتا تشكل أيضا تحديًا وقيدا بالنسبة لهيئة الوقف.

ومع ذلك يجدر التأكيد على أن العبرة لا تكمن في الصياغة الرياضية وفي الحسابات، بقدر ما تكمن في مدى بلوغ الأهداف المسطرة في كل مرحلة ولكل منطقة، فذلك هو 
نحو تطوير نظام شبكي للوقف الإسلامي المتناهي الصغر

المؤشر الحقيقي على فعالية تلك الميئات. فلا ينبغي إذاً التركيز على الأدوات والإجراءات وتغافل الأهداف والمستحقات، على أهمية الأدوات التنظيمية والمحاسبية والإحصائية والرياضية في تعزيز حوكمة المؤسسات الوقفية. إن خاصية الاستمرارية للأوقاف الصغرى، التي ترد لحظيا عبر مختلف قنوات التعبئة (نتحدث هنا عن أوقاف تودع في صناديق الوقف، أو تودع مباشرة لدى الجهات الوقفية،

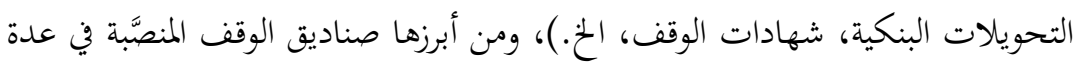

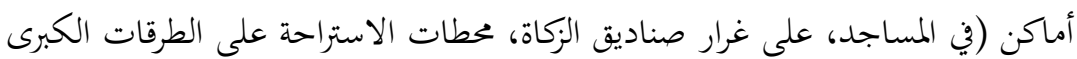
وبعض المرافق العامة المناسبة لذلك) تجعل من الوقف الأصغر دالة أسية. والدالة الأسية تعني أن المتغير يتطور عبر الزمن، ونعبر عن دالة رأس مال الأوقاف الصغرى

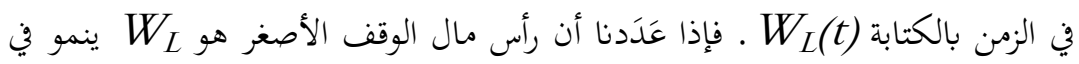
الزمن المستمر بمعدل ل، فإن تغير الوقف $\frac{d W_{L}}{W_{L}}(t)=j . d t$

$$
\frac{d W_{L}}{d t}(t)=J \cdot W_{L}(t) \Leftrightarrow d W_{L}(t)=W_{L}(t) . J d t
$$

وإذا كان لدينا رأس مال وقفي أساسي (O)

$$
W_{L(n)}=W_{L(0)} \cdot e^{J t}
$$

وعلى سبيل المثال إذ كان رصيد صندوق الوقف الأصغر في غاية السنة الثانية من تواجده هو 10 مليون، وكان متوسط المعدل السنوي المستمر المقدر لنمو الوقف بهذا الصندوق هو 10\%، فإن رصيد الصندوق في فهاية السنة السادسة يكون: $W_{L t_{6}}=W_{L t_{2}} \cdot e^{J\left(t_{6}-t_{2}\right)}=10 \times e^{0.1 \times 4}=14,9 M D$ 


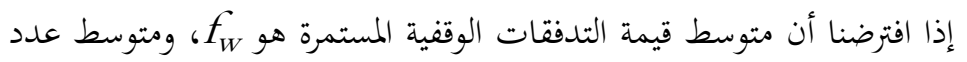

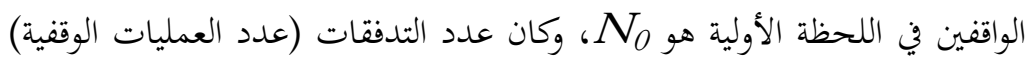
بمنطقة ما $i$ هو $i$ ها الإل $Z_{i} N_{0} f_{w} \cdot e^{j t} d t$

$$
W_{L}=Z_{i} N_{0} f_{w} \int_{0}^{1} e^{j t} d t=Z_{i} N_{0} f_{w} \frac{e^{j}-1}{j}
$$

إذا افترضنا أن هذه الموارد الوقفية المجمعة يتم استثمارها بمتوسط عائد سنوي مستمر

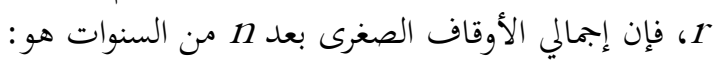

$$
\begin{gathered}
W_{L}(n)=\int_{0}^{n} Z_{i} N_{0} f_{w} \cdot e^{j t} e^{r(n-t)} d t \\
W_{L}(n)=Z_{i} N_{0} f_{w} \int_{0}^{n} e^{r n} e^{(j-r) t} d t
\end{gathered}
$$

يككن تمثيل ذلك من خلال الشكل التالي:

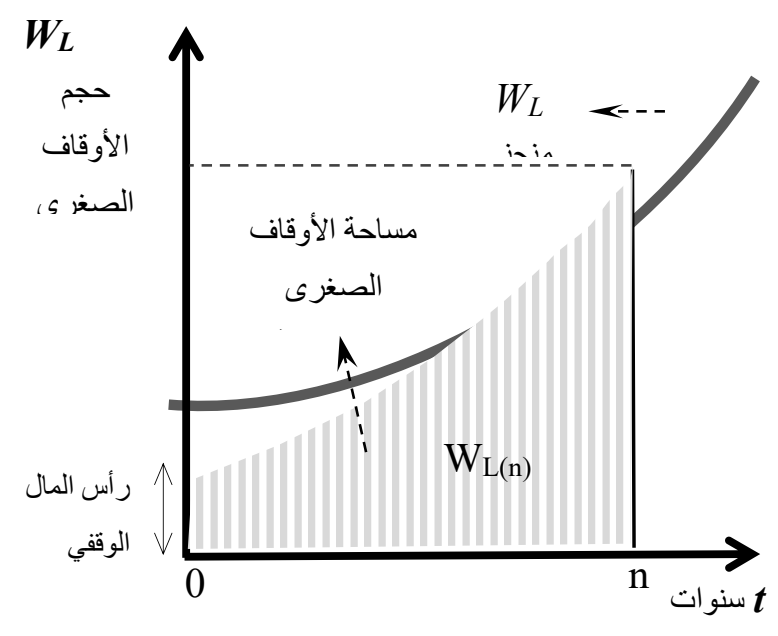

شكل (7): حساب حجم الأوقاف الصغرى لـ n سنة 
غو تطوير نظام شبكي للوقف الإسلامي المتناهي الصغر

وكمثال عن ذلك لو قدرنا متوسط التدفقات الوقفية

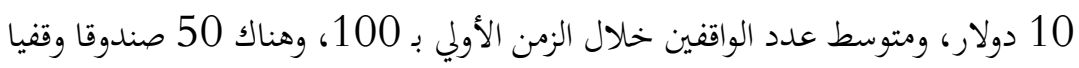

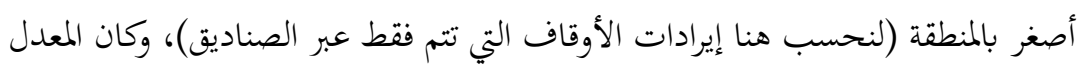

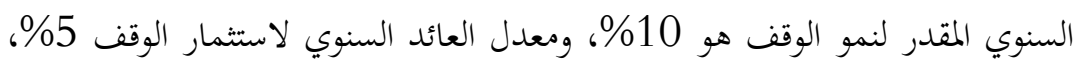

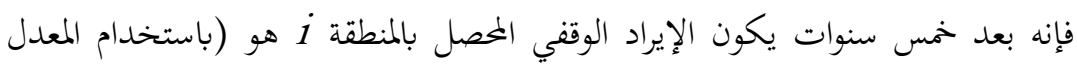

$$
\begin{aligned}
W_{L_{i}}(5)=50 \times & 10^{3} e^{0.048 \times 5} \int_{0}^{5} e^{0.047 t} d t \\
& =52406,1 \int_{0}^{5} e^{0.047 t} d t=295376,5 \$
\end{aligned}
$$

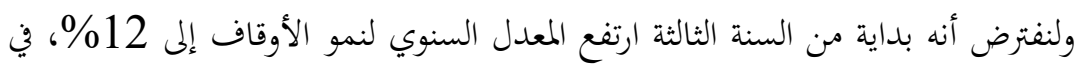

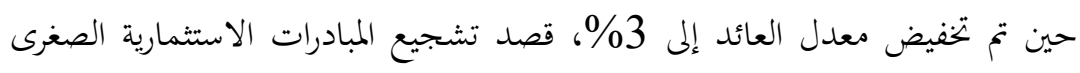

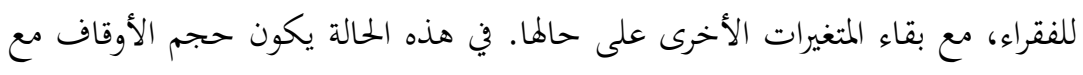

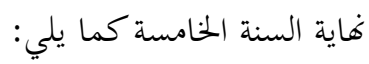

(1)- حجم الأوقاف المجمعة إلى ثاية السنة الثانية (سنتين) بمعدل نمو 10\% ومعدل عائد 5\%، باعتبار المعدلات المستمرة المكافئة (باستخدام المعدل المستمر):

$$
\begin{aligned}
W_{L_{i}}\left(t_{2}-t_{0}\right)= & 50 \times 10^{3} e^{0.048 \times 2} \int_{0}^{2} e^{0.047 t} d t \\
& =115408,75 \$
\end{aligned}
$$

(2)- حجم الأوقاف المجمعة من بداية السنة الثالثة إلى فاية السنة الخامسة (3 سنوات) بمعدل نمو 12\% ومعدل عائد 3\%، باعتبار المعدلات المستمرة المكافئة: 


$$
\begin{aligned}
W_{L_{i}}\left(t_{5}-t_{2}\right)_{(1)} & \\
= & 50 \times 10^{3} e^{0.029 \times 3} \int_{2}^{5} e^{0.081 t} d t \\
= & 217633,87 \$
\end{aligned}
$$

(3)- الأوقاف الصغرى المحصلة في فاية السنة 5 من استخدام الأوقاف المجمعة في هاية السنة الثانية بمعدل عائد سنوي 126110,25\%

$$
\begin{aligned}
& W_{L_{i}}\left(t_{5}-t_{2}\right)_{(2)}=115408,75 \times 1.03^{3}=126110,25 \$ \\
& \text { وبالتالي يكون مجموع الأوقاف الصغرى في فاية السنة الخامسة هو: } \\
& W_{L_{i}}(5)=115408,75+217633,87+126110,25 \\
& =459152,87 \$ \\
& \text { يمكن تمثيل هذه النتائج من خلال الشكل التالي: }
\end{aligned}
$$

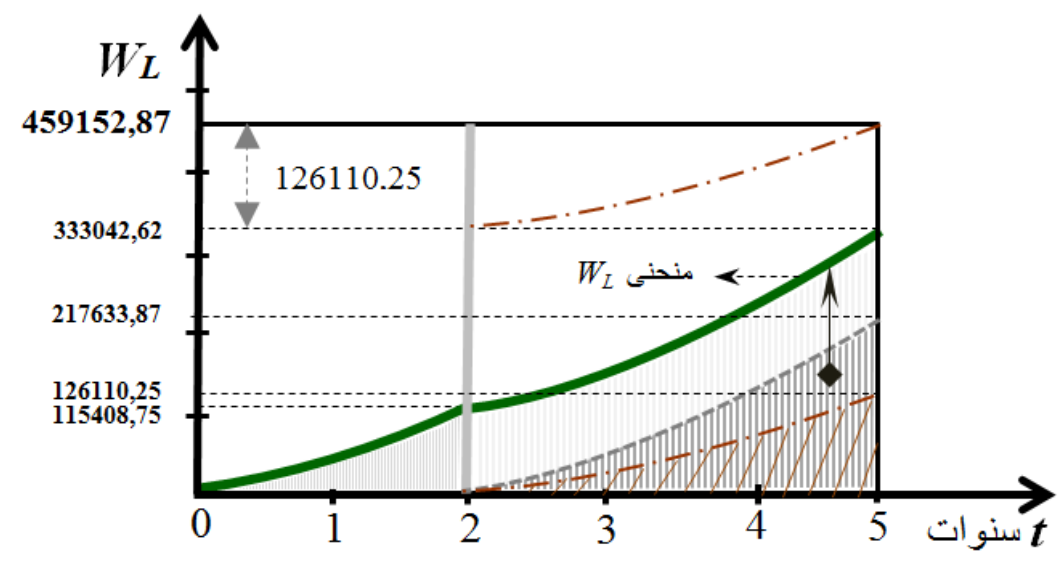

شكل (8): حساب حجم الأوقاف الصغرى لخمس سنوات وفقا للمعطيات المفترضة

ومن الملاحظ أنه على الرغم من تخفيض معدل عائد استخدام الأموال الوقفية (من 5\% إلى 3\%)، إلا أن حجم الأوقاف في غهاية السنة الخامسة كان أكبر 
نحو تطوير نظام شبكي للوقف الإسلامي المتناهي الصغر

(458746,8)، بالمقارنة مع الحالة الأولى (295376,5)، أي بزيادة 55\%، وهذا

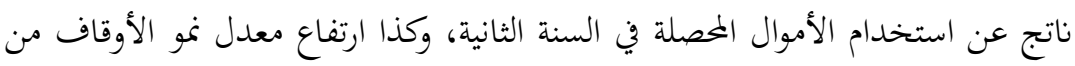

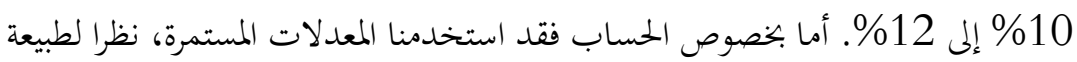

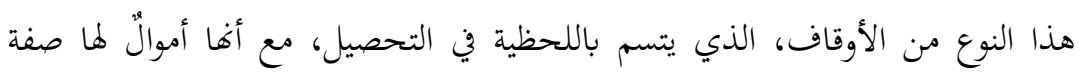
الديمومة.

وللتأكيد، فعلى الأهمية البالغة لمقصد تنمية الأوقاف ووجوب تقدير حصيلتها، فإن الأهم من ذلك هو سبل استخدام هذه الأوقاف والتحوط من مخاطر ضياعها أو تدهورها،

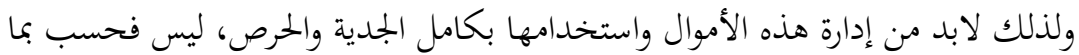
يوافق شروط الوقف وضوابط الشرع، ولكن أيضا بما يحقق تعظيم المنفعة الاجتماعية والاقتصادية.

\section{5- شبكات الوقف الأصفر: شروط قيامها ومتطلبات فعاليتها}

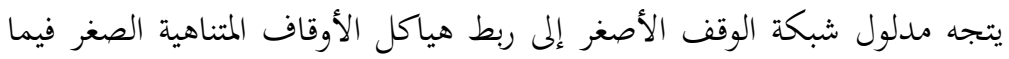

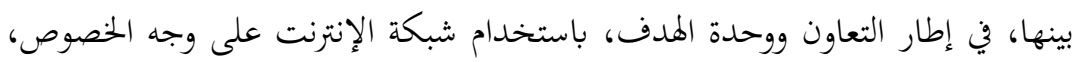
ولكن أيضا باستخدام كل وسائل الاتصال المتاحة. وكما تمت الإشارة في ما سبق من هذا لإنسا

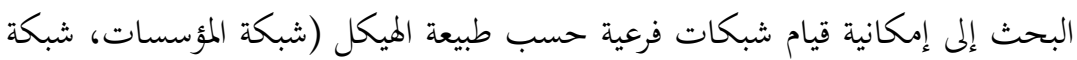
الصناديق، شبكة الجمعيات، شبكة منصات التمويل الوقفي، ...)، فإنه أيضا يمكن قيام شبكات حسب مجال الاهتمام، فنتحدث هنا عن شبكة مؤسسات الوقف الأصغر للدعم الاجتماعي، شبكة مؤسسات الوقف الأصغر للوقف الصحّي، شبكة مؤسسات الوقف الأصغر للتعليم والبحث العلمي، شبكة مؤسسات الوقف الأصغر لدعم المشروعات الصغرى، وغيرها. كما يمكن قيام شبكات، وفقا للمعيارين معا، أي: معيار طبيعة الهيكل

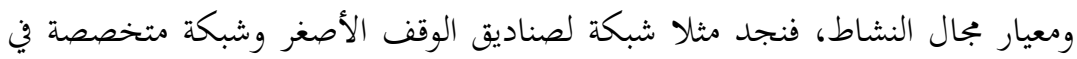
دعم المشروعات الصغرى للفقراء. وعموما فإن هذه الشبكات الفرعية ستتشكل منها في 
النهاية شبكة مدبجة للأوقاف الصغرى. فلو اعتدَدْنا بالمعيارين معا، يمكن تمثيل هذا التشكل الشبكي من خلال المخطط التالي:

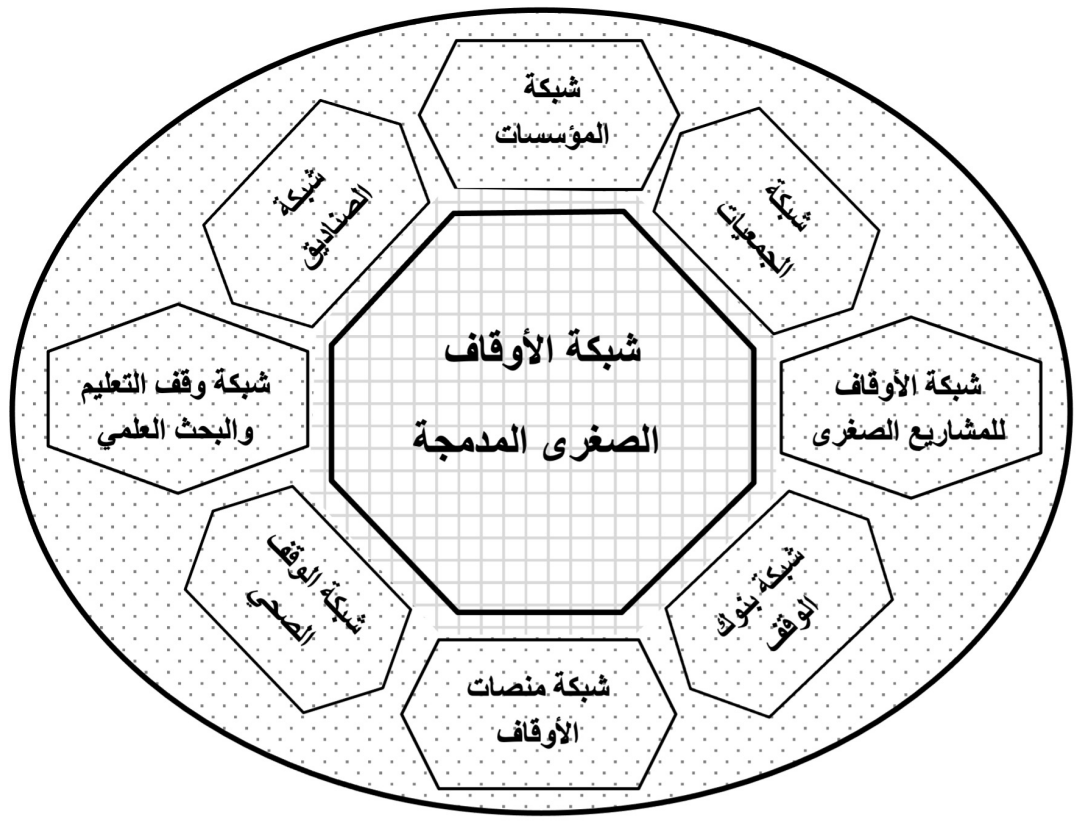

شكل (9): شبكات الأوقاف الصغرى والشبكة المدبجة

إنّ وجود شبكة إنترنت لتجسيد شبكة الأوقاف الصغرى يُعَدّ شرطًا ضروريًا، إلا أنه يبقى غير كاف لقيام هذه الشبكة وبلوغ المستوى المطلوب من الفعالية، فثمة مقومات وشروط أخرى لابد منها لتجسيدها وضمان فعاليتها. ففيما يتعلق بمقومات قيام هذه الشبكة وشروطها (شروط الوجود) ونجاحها، ينبغي التمييز ما بين: مقومات كلية، تتعلق بالميط، ومقومات جزئية: تتعلق بالهيئات والأفراد. وإجمالا نشير إلى ما يلي: 
نغو تطوير نظام شبكي للوقف الإسلامي المتناهي الصغر

وجود إطار تشريعي وتنظيمي ضابط للأوقاف الصغرى وشبكات الوقف الأصغر،

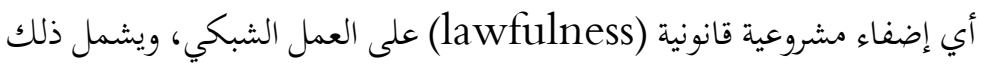
الإقرار بالوقف الإلكتروين وأدواته، بما في ذلك التوقيع الإلكتروني، اعتماديّة الهيئات

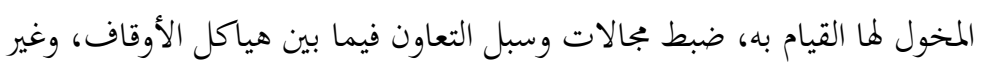
ذلك مما يرتبط بهذا النشاط. وجود إرادة للعمل التعاوين ما بين القائمين على هياكل الأوقاف الصغرى، والتي

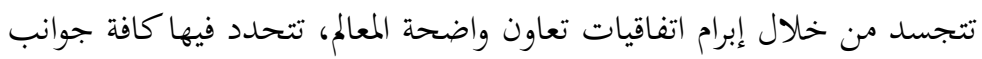
هذا التعاون وأشكاله، مع السعي لتجسيدها ميدانيا. ضمان وجود شبكة إنترنت عبر كافة المناطق التي تتواجد بها هذه الهياكل، وهو ما يعزز مبدأ الجوارية (proximity) والاقتراب من كل المناطق. توفير ضمانات أمنية الأموال والمعلومات، سواء بالنسبة للتدفقات الوقفية التي تتم عبر الشبكة، أو مختلف البيانات والمعاملات التي تتم عبرها.

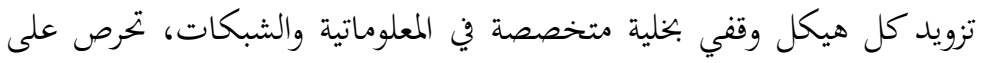
المتابعة المستمرة للشبكة، وتغذي إدارة هيكل الوقف الأصغر بالمعلومات المتاحة عبر الشبكة. ضمان شفافية المعاملات من خلال نشر تقارير دورية حول نشاط الشبكة (الإفصاح)، وهو ما من شأنه، فضلا، عن توفير المعلومات وتغذية قاعدة بيانات الأوقاف، أن يدعم الثقة في الهيئات الوقفية ويعزز ثقافة الوقف الأصغر . أما فيما يخص فعالية هذه الشبكة، والتي ترتبط بمدى تحقيق الأهداف المرجوة منها،

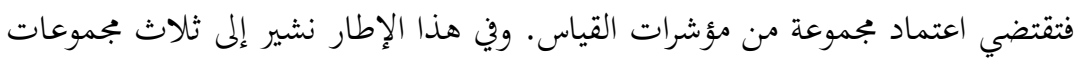

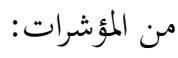


مؤشرات الامتداد الشبكي (Deployment)، ومن ضمنها: عدد المشتركين في الشبكة من الهيئات الوقفية، الانتشار الجغرافي للشبكة، ولاسيما في المناطق الداخلية والمحلية، عدد زوار الشبكة والمتفاعلين معها خلال فترة معينة. مؤشرات الاعتمادية والمرونة (Reliability \& Flexibility)، والتي تتعلق بقياس موثوقية النظام الشبكي، وهي تتيح قياس فعالية نشاط الوقف الإلكتروني، والتعاملات الإلكترونية المرتبطة بالوقف عموما، ومن ضمنها: عدد الواقفين

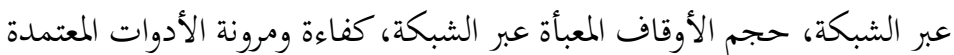
في الشبكة وملاءمتها لكل الفئات.

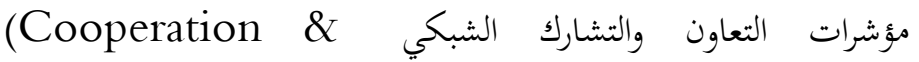
Collaboration) المشتركة، ومما تتضمنه هذه المؤشرات من دلالات: علد اتفاقيات التعاون وطبيعتها، عدد المشروعات الوقفية المنجزة أو الممولة بالتعاون، حجم التفاعلات ما بين الهيئات الوقفية عبر الشبكة، حجم التحويلات الوقفية ذات الطابع التعاوني عبر الشبكة، الخ. يمكن تلخيص هذه المقومات والمؤشرات من خلال الشكل الآتي:

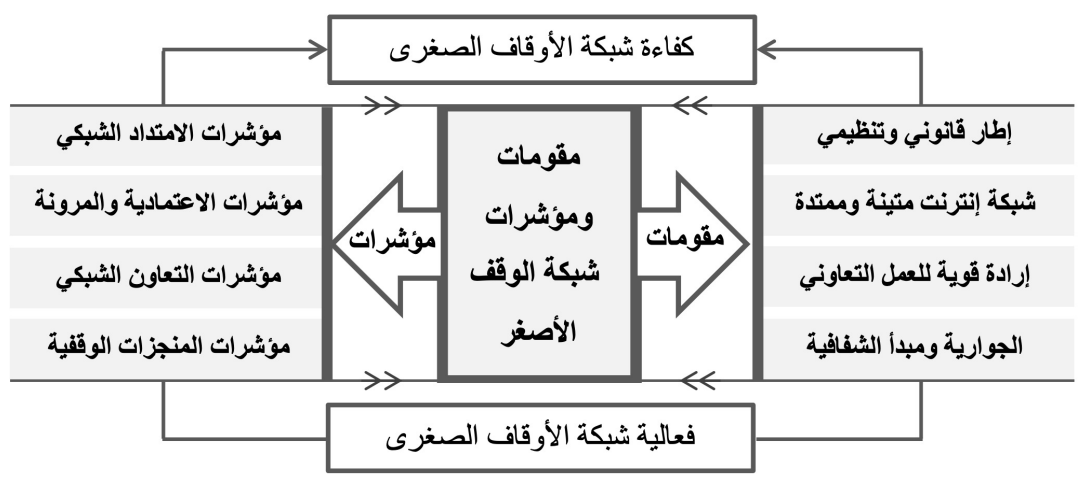

شكل (10): شبكة الوقف الأصغر: مقومات الوجود ومؤشرات الفعالية 
نغو تطوير نظام شبكي للوقف الإسلامي المتناهي الصغر

وعلى العموم فإن كفاءة نظام الوقف وفعاليته تستدعيان توفير قاعدة متكاملة من المتطلبات

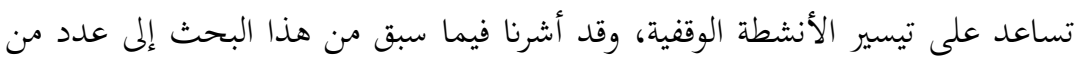

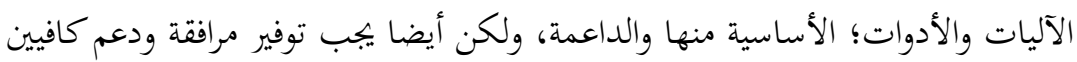
من جانب السلطات العمومية، سواء أكان دعما معنويا أم ماديا، ومن ذلك إرساء نظام إحصائي وطني للأوقاف، وهو ما يمكن إدراجه في المخطط أعلاه (شكل 10) ضمن الإطار التنظيمي، وكذا تقديم تسهيلات إدارية وتحفيزات مالية للمؤسسات الوقفية، هذا فضلا عن فرض تطبيق مبادئ الحوكمة وقواعد الإدارة الجيدة في هذه المؤسسات المالية غير الربحية.

الخاتمة:

لقد حاولنا عبر عناصر هذا البحث إبراز أهمية منظومة الأوقاف الصغرى، التي تكاد تكون بجهولة ومغمورة، ليس فحسب على مستوى الواقع، ولكن حتى على مستوى البحث الأكاديمي والاجتهاد الفقهي، في ظل شيوع ثقافة وقفية علقت العمل الوقفي بالأصول العقارية، على خلفية مدلول شرط ديمومة الأوقاف. فمع أن باب الوقف يظل من أكثر

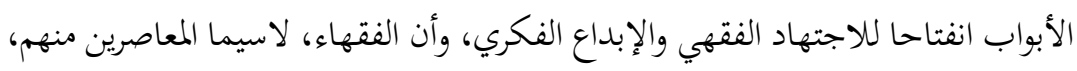
وسّعوا في مجال وقف المنقول، والوقف النقدي منه على وجه الخصوص، فإن تفعيل هذا

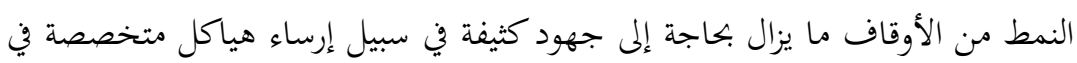
الوقف الأصغر، واستحداث تدابير وأدوات وقواعد تنظيمية من شأفها المساعدة في تطويره وتقديمه نموذجًا متكاملاً.

ثمة باحثون -على قلتهم- يستنكرون اعتبار الوقف آلية تمويلية ضمن آليات التمويل

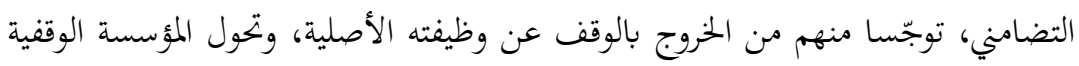

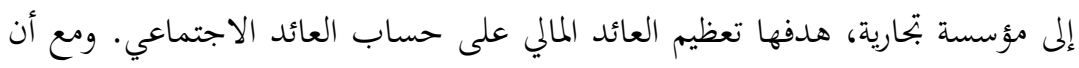
هذا التوجس الاحترازي مشروع، فإنّه لا ينبغي أن يتجه إلى تثبيط أية مبادرة تطويرية 
لمنظومة المالية التضامنية الإسلامية، وحتى الاستفادة من بعض جوانب التجربة الغربية في

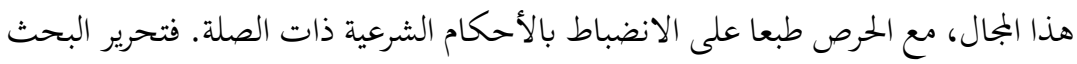
العلمي والاجتهاد الفقهي في حقل الوقف ضرورة أساسية لتطوير نظام الأوقاف، وبعث المؤسسة الوقفية بوجه جديد ووظائف أكثر شمولية وعصرنة.

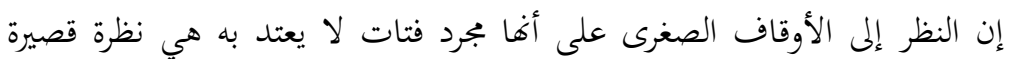
وقاصرة، ذلك أن العبرة في المجمّع لا في المفرد، إذ إن إدماج كل الفئات في النشاط الوقفي

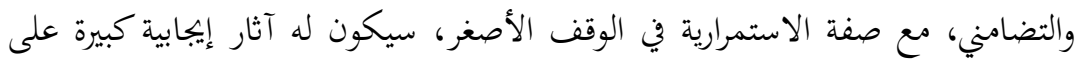

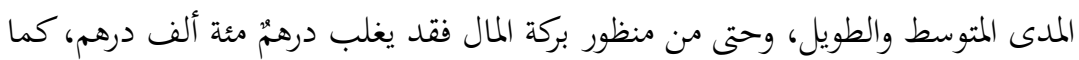
جاء في الحديث النبوي الذي أنفت الإشارة إليه، ولذلك، فإن أيّ مسار تطويري لنظام الوقف الإسلامي يغفل هذا النوع من الأوقاف يبقى مسارا أعرج. يمكن تلخيص أهم نتائج واقتراحات هذا البحث في النقاط التالية:

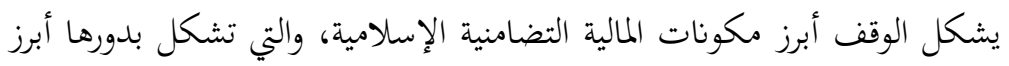

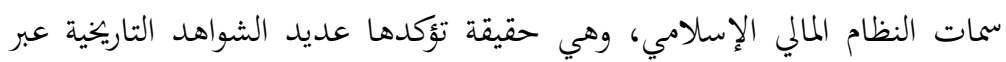

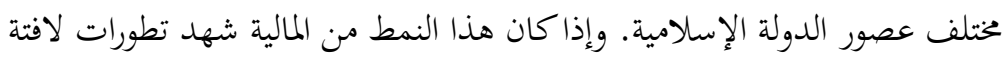
في الغرب، ضمن ما يعرف بالقطاع الخيري، فإن المجتمعات الإسلامية أحرى بتطويره. يتعين توجيه جهود تطوير نظام الوقف الإسلامي بالتزامن في مسارين متكاملين: وقف العقار ووقف المنقول، وهذا التطوير لن يتحقق إلا بالتطوير المستمر لهياكله لئه ومنتجاته، سواء من جانب تعبئة الأوقاف أو من جانب استخدام الموارد الوقفية.

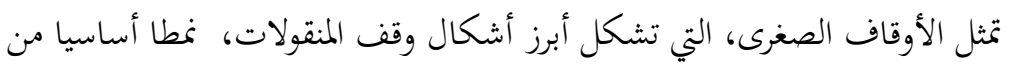
الوقف الإسلامي لا ينبغي تجاهله، وهي تشمل: النقد والعَيْن على حد سواء، بل ويمكن أن تشكل الأوقاف الصغرى منظومة قائمة بذاها، بآلياها وأدواتها الخاصة.

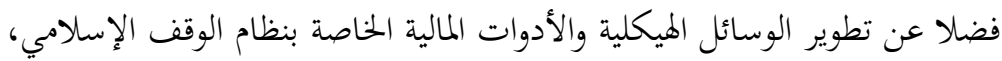
ينبغي أيضا تعزيز الإدارة الوقفية بالأدوات الكمية والمحاسبية ومختلف فنون الإدارة 
نغو تطوير نظام شبكي للوقف الإسلامي المتناهي الصغر

الحديثة، دعما لمكانتها ودورها الاجتماعي والاقتصادي، وترقيةً لفعاليتها وحسن حوكمتها.

يعتبر التمويل الوقفي للمشروعات الصغرى للفقراء مدخلا أساسيا في تحقيق الوظيفة الاجتماعية للوقف، فضلا عن أنه يعد إسهاما مباشرا في التنمية الاقتصادية، وهو يندرج في صميم مقاصد الوقف الإسلامي. وتفعيلا لهذا الدور نقترح إقامة هياكل متخصصة في التمويل الوقفي الأصغر لمشروعات المبادرين من الفقراء.

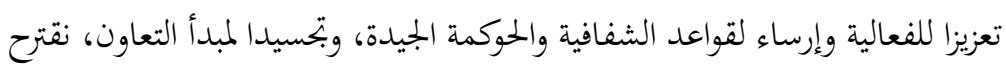
إقامة شبكة لهياكل الوقف الإسلامي الأصغر، وقد تتحول إلى شبكة شاملة لكافة

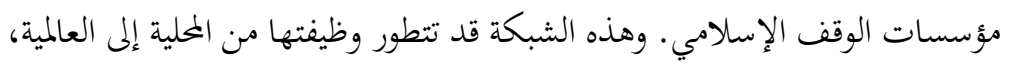

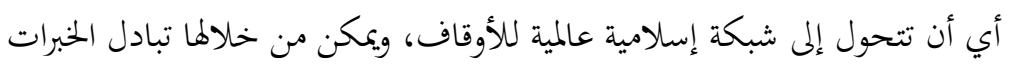

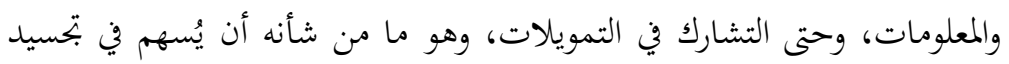
مبدأ التكافل الإسلامي بمنظور عالمي، وبتسيد مبدأ وحدة الأمة الإسلامية.

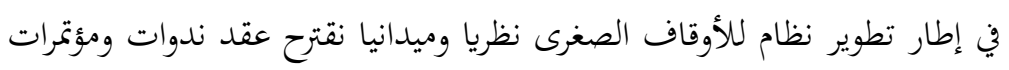

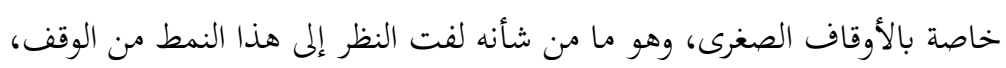

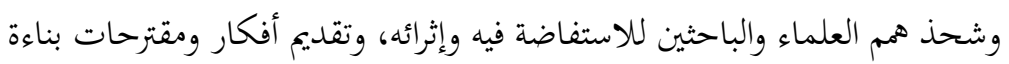
تُسهم في مجموعها في تشكيل هذا النظام. وفي ختام هذا البحث يجدر الذكر أن موضوع الوقف الأصغر، كونهُ فرعًا ضمن فئن فئن

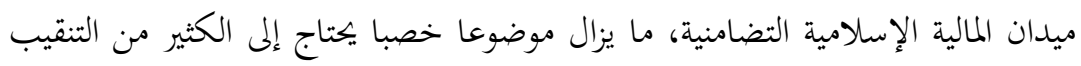
والتطوير في مختلف جوانبه: الشرعية والاقتصادية والاجتماعية والإدارية والمالية والمحاسبية، مئه

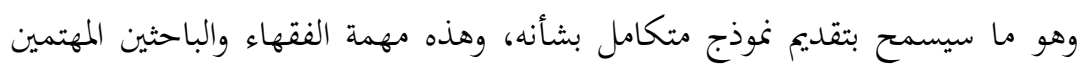
بمجال الوقف والمالية الإسلامية عموما. فإذا كانت الزكاة قد استحوذت على القسط الوفير من البحث، وأنشئت لها صناديق خاصة، وتم توسيع مصارفها إلى مشروعات الفقراء، فإِان الوقف، وهو الأوسع نطاقا، يبقى بحاجة إلى مزيد من البحث الأساسي والتطوير الميداني. 
- الزحيلي، محمد. الصناديق الوقغية المعاصرة: تكسيفها، أشكالها، حكمها، مشكلاتما. بحث منشور في:

www.kantakji.com/fiqh/Files/Wakf/52054.pdf

- الصلاحات، سامي (1426 هـ/2005م). دور المؤسسة الوقفية في تنمية المجتمعات الإسلامية المعاصرة. مجلة جامعة الملك عبد المبات العزيز.

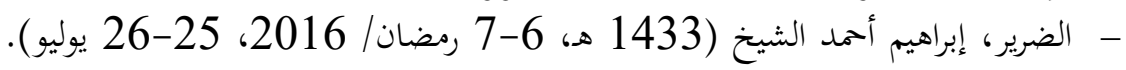

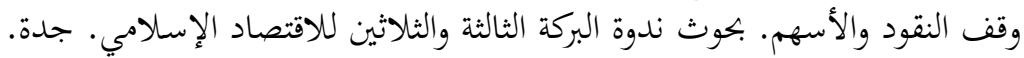

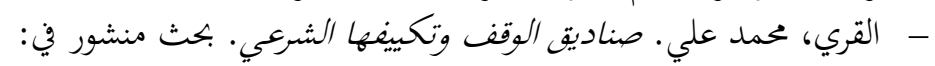
http://www.elgari.com/?p=1467

- الوكالة الوطنية لتسيير القرض المصغر ANGEM. ما هو القرض المصغر؟، في: https://www.angem.dz/ar/page/qu-est-ce-que-le-micro-credit/

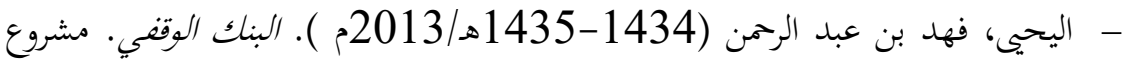

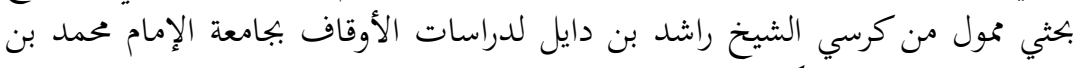
سعود الإسلامية، المملكة العربية السعودية.

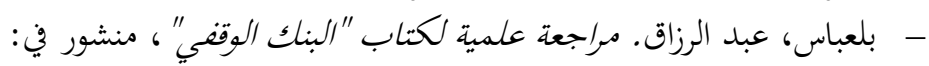
https://www.academia.edu/29367268/

$$
\text { - - بلعباس، عبد الرزاق (2016). تمويل الأوقاف بالحشود، منشور في: }
$$
https://www.academia.edu/attachments/50557156/

- - بلوافي، أحمد مهدي (2010). البنك الوقفي: هل هي فكرة قابلة للتطبيق؟. بحث منشور

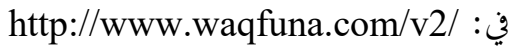

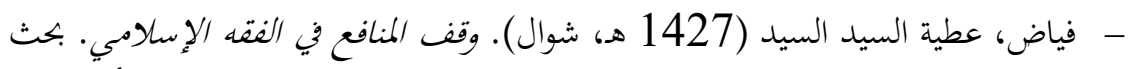

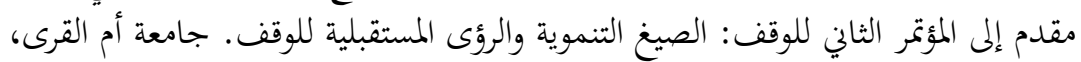
مكة المكرمة.

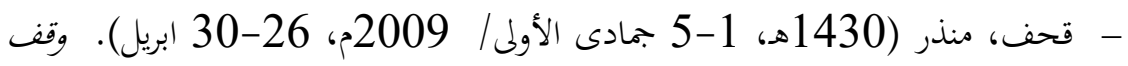

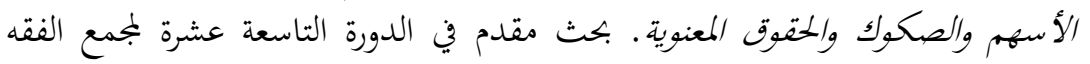

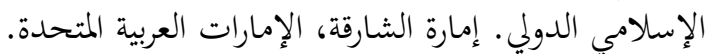

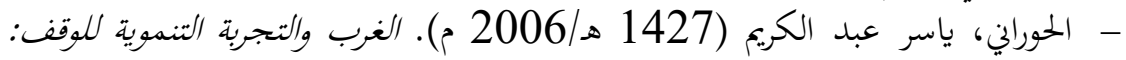

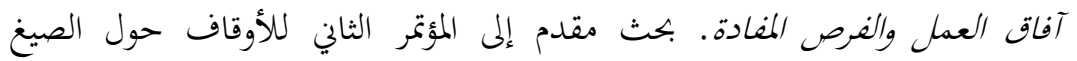


التنموية والرؤى المستقبلية المنعقد في رحاب جامعة أم القرى، المملكة العربية السعودية. - الهيئة المحاسبة والمراجعة للمؤسسات المالية الإسلامية، المعيار الشرعي رقم (33) بخصوص الوف الوقف. - - مجمع الفقه الإسلامي الدولي:

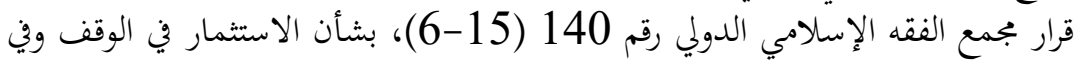

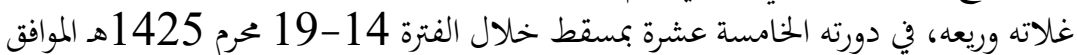

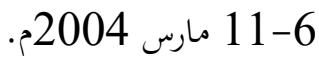

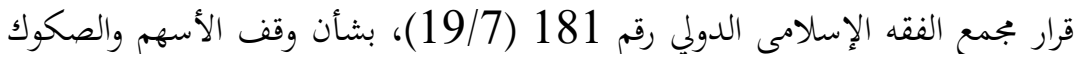

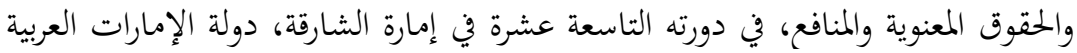

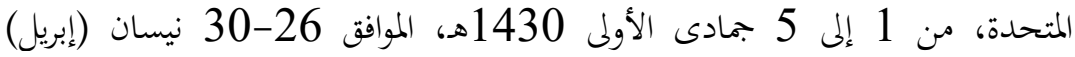
2009 - هزاع، ماجدة محمود (1427هـ، شوال). الوقف المؤقت: بحث فقهي مقارن، المؤتمر الثاني

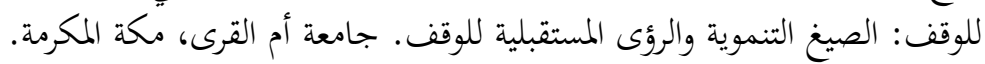

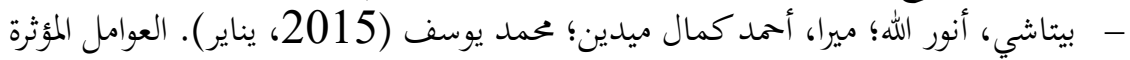

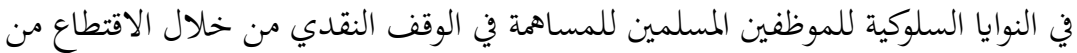

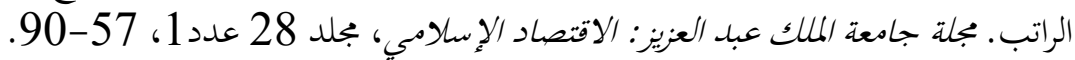

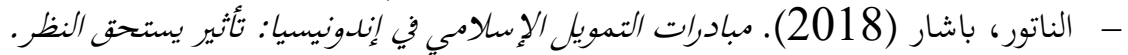

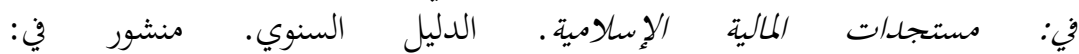
https://www.islamicfinancenews.com/download/229912/

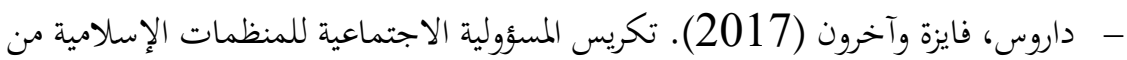

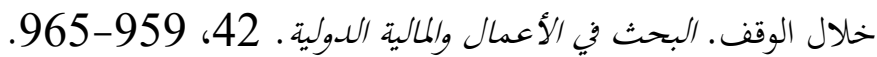

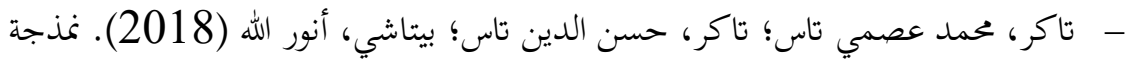

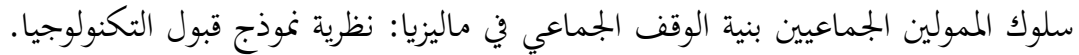

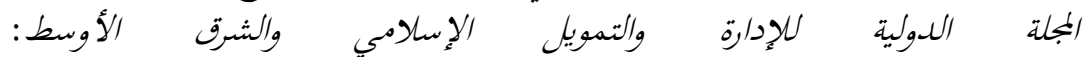
https://doi.org/10.1108/IMEFM-06-2017-0157 - هامبر، نورليانا محمد (2017، يناير). الصندوق الاجتماعي الأصغر القائم على الوقف:

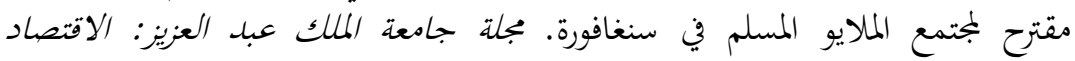

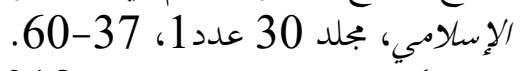
- تقرير تكنولوجيا المالية للنظام البيئي 2018. 
https://www.fintechgalaxy.com/storage/uploads/reports/2018/08/08/31b 03ebdf443501b54fb107285a6da4f.pdf

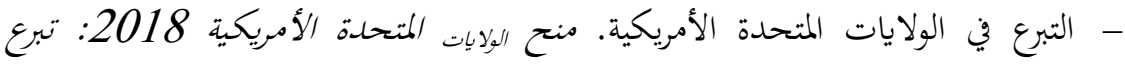

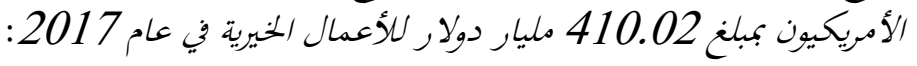

https://givingusa.org/giving-usa-2018-americans-gave-410-02-billion-

to-charity-in-2017-crossing-the-400-billion-mark-for-the-first-time/

$$
\text { - ازدهار العمل الخيري. منشور في صحيفة لوموند بتاريخ } 06 \text { يونيو 2017. في: }
$$

https://www.lemonde.fr/argent/article/2017/06/06/la-philanthropie-enplein-essor_5139449_1657007.html

- CAF 2018 : https://www.cafonline.org/docs/default-source/about-uspublications/caf_wgi2018_report_webnopw_2379a_261018.pdf

\section{References}

Accounting and Auditing Orgainization for Islamic Financial Institutions (AAOIFI), Governance Standard 13 Waqf Governance.

Agence Nationale de gestion du Micro-crédit (ANGEM). Qu'est-ce que un micro-crédit? Retrieved from: https://www.angem.dz/ar/page/quest-ce-que-le-micro-credit/

Al Darir, Ibrahim Ahmed Ash Sheikh (2016, 6-7 Ramadan 1433H/2526 July 2016). Cash and shares waqf. Al Baraka $33^{\text {rd }}$ symposium of the Islamic economic. Jeddah.

Al Hurani, Yassir Abdelkarim (1427H/2006). The West and the developmental experience of Waqf: Practice prospects and learned opportunities. Presented at a second conference of awqaf: the development formulas and future visions. Umm AlQura University, Kingdom of Saudi Arabia.

Al Natoor, Bashar (2018). Indonesia's Islamic finance initiatives: Impact to be seen. in: Islamic Finance News (IBF). Annual guide. Retrieved from : https://www.islamicfinancenews.com/download/229912/

Al Qari, Muhamed Ali. Waqf funds and their Shari'ah adaptation. Retrieved from: http://www.elgari.com/?p=1467 
نغو تطوير نظام شبكي للوقف الإسلامي المتناهي الصغر

Al Salahat, Sami (1426H, 2005). The role of waqf institution in the development of contemporary Islamic societies. King Abdulaziz university review.

Al Yahya, Fahd Ben Abderrahmane (1434-1435H/2013). The waqf bank. A research project funded by Al Sheikh Rached ben Dayel Chair for Awqaf Studies at Imam Mohamed ben Saoud Islamic University, Kingdom of Saudi Arabia.

Al Zuhaili, Mohamad. Contemporary waqf funds; their adaptation, forms rule and their problems. Retrieved from: www.kantakji.com/fiqh/Files/Wakf/52054.pdf

Belabbas, Abderrazak (2016). A scientific review of the book «waqf bank», retrieved from: https://www.academia.edu/29367268/

Belabbas, Abderrazak (2016). Financing Awqaf by crowds, retrieved from:: https://www.academia.edu/attachments/50557156/

Belouafi, Ahmed Mehdi (2010). Waqf bank: Is it a viable idea? In: http://www.waqfuna.com/v2/

Charities Aid Foundation, World Giving Index 2018. Retrieved from https://www.cafonline.org/docs/default-source/about-uspublications/caf_wgi2018_report_webnopw_2379a_261018.pdf

Darus, Faizah et al (2017). Empowering social responsibility of Islamic organizations through Waqf. Research in International Business and Finance, 42, 959-965.

Fiad, Atia Seid Seid (1427H, Choual). Waqf of benefits in Islamic jurisprudence. Paper presented at a $2^{\text {nd }}$ conference of waqf: Development formulas and future visions of the Waqf. Umm Al Qura University, Makkah.

Giving USA: "Giving USA 2018: Americans Gave \$410.02 Billion to Charity in 2017": https://givingusa.org/giving-usa-2018americans-gave-410-02-billion-to-charity-in-2017-crossingthe-400-billion-mark-for-the-first-time/

Hamber, Norliana Mohammad (2017, January). Waqf-Based Social Micro Venture Fund: A Proposal for the Malay-Muslim Community in Singapore. JKAU: Islamic Econ., Vol. 30 No. 1, 37-60.

Hazaa, Majda Mahmoud (1427H, Choual). The Temporary waqf: A Comparative Jurisprudence Study, The $2^{\text {nd }}$ waqf conference: 
development formulas and future visions of waqf. Umm Al Qura University, Makkah.

International Islamic Fiqh Academy: Resolution No. 140 (15/6) on investment in awqaf and its yields and rents. 15th meeting of IIFA. Muscat, 1425H, 14-19 mouharram /2004, 6-11 March. Sultanate of Oman.

International Islamic Fiqh Academy: Resolution No. 181 (7/19) on waqf of shares, Sukuk, intangible moral and usufruct in its 19th meeting: 1430H, 1-5 Joumada'1/ 2009, 26-30 April. United Arab Emirates.

Kahf, Monzer (1430H, 1-5 Jumada 1/2009, 26-30 April). Waqf of shares and sukuk and intangible moral. Paper presented at a $9^{\text {th }}$ session of the International Islamic Fiqh Academy. The Emirate of Sharjah, United Arab Emirates.

Lelong, Patrick and Porier, Jérôme (2017, 6 Jun.). Philanthropy Flourishing, published in Le Monde. Retrieved from https://www.lemonde.fr/argent/article/2017/06/06/laphilanthropie-en-plein-essor_5139449_1657007.html

Pitchay, Anwar Allah; Meera, Āhamed Kameel Mydin; Saleem, Muhammad Yusuf (2015, January). Factors Influencing the Behavioral Intentions of Muslim Employees to Contribute to Cash-Waqf Through Salary Deductions. JKAU: Islamic Econ., Vol. 28 No. 1, 57-90.

Thaker, Mohamed Asmy Mohd Thas, Thaker, Hassanudin Mohd Thas; Pitchay, Anwar Allah (2018). Modeling crowdfunders' behavioral intention to adopt the crowdfunding-waqf model (CWM) in Malaysia: The theory of the technology acceptance model. International Journal of Islamic and Middle Eastern Finance and Management, Vol. 11, No. 2, 231-249

Waqf. Research in International Business and Finance, 42, 959-965 